\title{
Freshwater Export from the Labrador Current to the North Atlantic Current at the Tail of the Grand Banks of Newfoundland.
}

\author{
Paula S. Fratantoni* and Michael S. McCartney
}

Department of Physical Oceanography

Woods Hole Oceanographic Institution

Woods Hole, MA 02543

Deep Sea Research Part I. 57 (2) : 258-283. 10.1016/j.dsr.2009.11.006

* Corresponding author: Dr. Paula S. Fratantoni, Tel 508-289-2631; Fax 508-457-2181

Email: pfratantoni@whoi.edu 


\section{Abstract}

Historical hydrographic data, spanning the period 1896-2006, are used to examine the annual mean and seasonal variations in the distribution of freshwater along and across the shelf/slope boundary along the Labrador and Newfoundland Shelves and the Grand Banks of Newfoundland. Particular attention is paid to the export of freshwater along the eastern Grand Banks, between Flemish Cap and the Tail of the Grand Banks, as this has long been identified as a preferential region for the loss of mass and freshwater from the boundary. The data are combined into isopycnally averaged long-term annual and monthly mean gridded property fields and the evolving distribution of fresh arctic-origin water is analyzed in fields of salinity anomaly, expressed as departures from the "central water" temperature-salinity relation of the Gulf Stream. The climatology confirms that cold/fresh northern-source waters are advected offshore within the retroflecting Labrador Current along the full length of the boundary between Flemish Cap and the Tail of the Grand Banks. In fact, it is estimated that most of the equatorward baroclinic transport at the boundary must retroflect back toward the north in order to explain the annual mean distribution of salinity in the climatology. While the retroflection of the Labrador Current appears seasonally robust, the freshwater distribution within the retroflection region varies in response to (1) the freshness of the water available for export which is set by the arrival and rapid flushing of the seasonal freshwater pulse at the boundary, (2) seasonal buoyancy forcing at the surface which alters the vertical stratification across the retroflection region, restricting certain isopycnal export pathways, and (3) the density structure along the eastern Grand Banks, which defines the progressive retroflection of the Labrador Current.

Keywords: Labrador Current; subpolar gyre; freshwater; North Atlantic Current; Boundary current retroflection. 


\section{Introduction}

The boundary between the coastal and open-ocean regimes of the western North Atlantic is characterized by a sharp thermohaline front, separating cold, fresh shelf waters from warmer and saltier interior water masses. The shelf waters are comprised of a combination of regional coastal discharge and Arctic-origin water, including freshwater input from the Greenland glaciers. The thermohaline front is generally centered near the shelfbreak and supports a persistent surface-intensified current that is identifiable along a $6000 \mathrm{~km}$ path following the boundary counter-clockwise around the Labrador Sea and southward along the east coast of North America (Sverdrup, 1942). The current has many regional names (e.g. West Greenland Current, Labrador Current, shelf/slope jet, shelfbreak current), but tracer observations suggest that it is a single large-scale feature capable of transporting high-latitude climate-driven signals equatorward between the subpolar and subtropical domains (Chapman and Beardsley, 1989). Recent observations suggest that the dynamics of this coastal boundary current may dictate where freshwater is discharged from the shelf, and that the exchange may be limited to a few specific locations along the path of the current (Loder et al, 1998; Fratantoni and Pickart, 2007). Of utmost importance is where, and by what mechanisms, this freshwater enters the interior Atlantic. Because deep convection in the North Atlantic and its associated Atlantic meridional overturning circulation (AMOC) are sensitive to where and how much freshwater is added to the interior gyres, understanding the behavior and dynamics of this current will enhance our ability to predict the manner in which climate-driven variability might impact the AMOC in the future. 
Recent studies indicate that as much as $90 \%$ of the total volume and freshwater transport that arrives on the Labrador Shelf in the shelfbreak current is lost between here and the Middle Atlantic Bight (Loder et al., 1998; Fratantoni and Pickart, 2007). It has been inferred from observations that particularly large transport losses occur in the vicinity of the Grand Banks of Newfoundland, presumably where a significant but unknown portion of the shelfbreak current (regionally called the Labrador Current, LC) retroflects offshore (Smith et al., 1937; Csanady and Hamilton, 1988), carrying with it a portion of the coldest, freshest Arctic-origin water into the interior (Figure 1). Very fresh retroflected LC water has been observed synoptically, returning north along the inshore edge of the much saltier North Atlantic Current (e.g. Figures 2 and 9 in Kieke et al., 2009). However, the precise location and reason for the loss of mass and freshwater by the LC are not well determined.

In the vicinity of the Grand Banks the shelfbreak shoals by nearly $300 \mathrm{~m}$, the shelf broadens considerably, and the upper continental slope steepens by a factor of two. These abrupt changes in topography alter the cross-shelf distribution of temperature and salinity, and appear to force a large portion of the LC onto the upper slope (Fratantoni and Pickart, 2007). In addition to topographic changes, the orientation of the shelfbreak changes abruptly at the Tail of the Grand Banks (Figure 1). In a climatology of synoptic sections described by Fratantoni and Pickart (2007), a majority of the cold (fresh) water located over the upper slope at the Grand Banks does not appear in Scotian Shelf sections downstream. The observations suggest that the Grand Banks is a preferred region for offshore exchange and hence a critical region on which to focus when looking at the propagation of climate signals in the North Atlantic.

It has been assumed that the most dramatic climate-cooling event to occur in the last 10,000 years was caused by the draining of glacial Lake Agassiz and the subsequent formation of a 
freshwater cap over the North Atlantic (Keigwin et al., 2005). Depending on the timescale of release, it has been estimated that the drainage could be as great as $\sim 5 \mathrm{~Sv}$ of freshwater exiting Hudson Strait (Teller et al., 2002), roughly half the total present-day volume transport of the LC (Lazier and Wright, 1993). Until recently little attention was paid to how this massive volume of freshwater may have been transported from the shelf near Hudson Strait into the North Atlantic. Modeling studies employing so-called "hosing" techniques have explored the impact of freshwater capping in the North Atlantic, demonstrating that by applying a freshwater anomaly over a large, convectively active, area the AMOC can be completely shut down (Manabe and Stouffer, 1997; Renssen et al., 2002). However, recent analysis of model results suggest that, even a large volume of freshwater exported from the Canadian Archipelago will not spread offshore directly, but will be forced to follow the shelfbreak southward along the coast, finally entering the interior along the Grand Banks (Myers, 2005; Condron et al., 2009). This is a profound result since, following this extended advection pathway, the freshwater leaves the boundary at the southern limit of the subpolar gyre, entering the interior adjacent to the North Atlantic Current (NAC) which carries a large volume of very salty water. In this scenario, one wonders if the water will be fresh enough upon reaching convection sites in the North Atlantic to affect the AMOC (P. Winsor, pers. comm.) This raises the question: What role does the LC play in the propagation of climate signals and how/where do such anomalies leave the coast to impact the North Atlantic?

While observations suggest that the Tail of the Grand Banks represents a choke point for communication of climate variability between the subpolar and the subtropical regions, our understanding of the current branching (e.g. transport partitioning) and controlling dynamics of even the mean circulation in this region is limited (Loder et al., 1998). Furthermore, 
observations suggest that the amplitude of seasonal variations of freshwater in this region can be as large or larger than inter-annual variations (Petrie et al., 1991; Petrie et al., 1992; Colbourne and Foote, 2000). For perspective, seasonal salinity variations in the LC approach 0.5 near the surface along the eastern Grand Banks (Petrie et al., 1991). This is comparable to the magnitude of freshening that has been attributed to the so-called Great Salinity Anomaly from the 1970s (Dickson et al., 1988). We can not possibly hope to identify or interpret the effects of interannual variability at this location without a thorough understanding of the mean circulation and property distributions as well as their seasonal variations.

In this study, we use 100 years of historical hydrographic data to construct a detailed description of the mean seasonal evolution of freshwater pathways between the Labrador Shelf and the Grand Banks of Newfoundland, focusing in particular on the export of freshwater along the eastern Grand Banks and at the Tail of the Grand Banks. The ultimate goal is to provide a robust climatological description of freshwater pathways in a geographic region where potentially large quantities of mass and freshwater enter the interior of the Atlantic. This information will provide a baseline for the identification of truly anomalous conditions, both past and future freshening events, with proper allowance for the large seasonal cycle, and to assess their impact on the larger climate system (e.g. the often cited scenario where the AMOC is shut down by low salinity waters covering convection regions in the North Atlantic, e.g. Manabe and Stouffer, 1997; Renssen et al., 2002).

We begin with a description of the data and our methods for constructing a climatology from historical hydrography in the region. Next we describe the two-dimensional seasonal mean evolution of freshwater between the Labrador Shelf and the Tail of the Grand Banks. We present an interpretation of the seasonal changes in the along- and cross-shelf distribution of freshwater 
that is based on the interplay between the seasonal cycle of freshwater input to the shelf, the distribution of salinity within the LC itself, and the effect of buoyancy forcing by the atmosphere on retroflection pathways in the region. We interpret the distribution of freshwater relative to mean dynamic topography in the retroflection region which is dominated by offshore geostrophic shear between Flemish Cap and the Tail of the Grand Banks. Last, we use the climatological distribution of salinity south of Flemish Cap to predict how much of the LC transport returns north with the NAC, and how far offshore we expect to find this relatively fresh water mixing with the NAC.

\section{Data and Methods}

In this study, we employ two methodologies to examine the patterns of freshwater advection by the Labrador Current: (1) climatological averaging of historical data and (2) identification of freshwater pathways through the analysis of salinity anomaly fields. Climatological fields presented here were constructed using the quality-controlled station data and isopycnal averaging techniques from HydroBase2 (Curry, 1996), itself based upon techniques developed by Lozier et al. (1995) for the construction of a North Atlantic climatology. The historical data span 110 years (1896-2006), although the majority of data were collected between 1970 and the present (Figure 2). Observations include conductivity temperature and depth (CTD) and bottle data from the World Ocean Database 2005 and individual experiments (personally provided to Curry), as well as profiling float data from ARGO. The temporal and spatial distribution of data within our study region is shown in Figure 2. The Grand Banks region between Flemish Cap and the Tail of the Grand Banks is particularly well-sampled historically. This is due in part to (1) the extensive International Ice Patrol surveys covering the shelf and upper slope over the Grand Banks, undertaken in response to the sinking of the Titanic in 1912 (Soule, 1940), (2) repeated 
surveys along 13 sections crossing the Newfoundland and Scotian Shelves completed seasonally by the Atlantic Zone Monitoring Program beginning in the late 1990s (Therriault et al., 1998), and (3) an extensive collection of repeat hydrographic sections occupied by the USSR in a regional grid offshore of the Grand Banks (The "Sections Program", Mikhailov et al., 2002). Note that, while there are generally more observations collected during the "summer" period, the mapped data distribution is slightly misleading in winter. In Figure 2, we only count stations that include observations within the upper layer (bounded by the $\sigma_{0}=26.80$ isopycnal which we justify later). This layer outcrops in the north during winter, partially accounting for the low station counts here during this time of year. In addition, a significant fraction of the Labrador and northeastern Newfoundland Shelves are ice-covered between January and March (Stroeve and Meier, 2008).

\subsection{Isopycnal Averaging}

Using the utilities provided with HydroBase2, monthly data were spatially binned, averaged and interpolated onto a standard grid with $20 \mathrm{~km}$ spacing over the domain shown in Figure 1. The gridding of scattered data is accomplished by averaging along density surfaces rather than pressure surfaces. The rationale is that water tends to mix along isopycnal, not isobaric, surfaces. Hence, working in isopycnal coordinates emphasizes isopycnal, over diapycnal, mixing. This is particularly important in the vicinity of fronts where the isopycnals are sharply sloped, as is the case in our study domain. Lozier et al. (1994) presented a striking example of the effect of isobaric averaging in the vicinity of the Gulf Stream, showing that this method produces artificial water masses with properties that are markedly different from the local water masses. In fact, they note that the artificial anomalies that are produced can be as large as the true basin-scale water mass anomalies that have been observed in the North Atlantic. In another 
study, Kulan and Myers (2009) produced high-resolution climatologies for the Labrador Sea using isopycnal and isobaric averaging techniques, concluding that the isopycnal product better preserved the structure of the density front and characteristic freshness of the water masses in the LC.

In order to examine the impact of isobaric averaging in the study region around the Tail of the Grand Banks, we have computed isopycnal and isobaric averages from a collection of six synoptic hydrographic sections along the WOCE repeat survey line, AR19. This section crosses the continental slope on the east flank of the Grand Banks near $43.5^{\circ} \mathrm{N}$ (Figure 1). The average sections and T-S relationships contain many of the same artifacts that have been highlighted in previous studies, including a broadening of the property front in the isobaric average and the creation of salty water mass anomalies within the NAC (Figure 3a,b,c). The water mass anomalies are immediately recognizable in the NAC (as was the case in the Gulf Stream), where isobarically averaged T-S values (orange) fall outside the range of the synoptic scatter (black) and lie outside the standard T-S curve for Western North Atlantic Central Water (Armi and Bray, 1982). However, the averaging artifacts are not as easy to identify inshore of this location, in the region between the "pure" LC and subtropical water masses. Instead, they have properties similar to the true Mixed Water (Soule, 1940) found in this part of the domain. By isopycnally averaging, we minimize the artificial mixing of water masses introduced by the averaging process so that we may confidently interpret the distribution of LC, Mixed, and NAC water masses in the climatology.

The two averaging techniques also have different effects on the shape of the isopycnals, particularly in the vicinity of the two predominant fronts in the region - that associated with the LC flowing south along the boundary and that associated with the NAC flowing north offshore 
(Figure 3a,b). Nearshore, the single isopycnal shown in both sections rises sharply with offshore distance. In the isopycnally averaged section the density surface remains relatively flat before descending almost monotonically offshore, except for the slight uplift near $350 \mathrm{~km}$ (Figure 3a). By contrast, in the isobarically averaged section the isopycnal is sharply peaked near $200 \mathrm{~km}$ and $375 \mathrm{~km}$, reaching depths that are up to $100 \mathrm{~m}$ shallower than those in the isopycnally averaged section (Figure 3b). The profiles of density near $375 \mathrm{~km}$, where these differences are maximized, indicate that the impact of isobaric averaging on the density field is not necessarily uniform with depth (Figure 3d). Instead, in this case isobaric averaging has artificially destratified portions of the water column, creating potential vorticity anomalies that could easily be misinterpreted as mode water in the isobarically averaged sections. While these potential vorticity anomalies are red flags, the impact of the distorted density structure on calculated geostrophic shear might go un-noticed. These are important artifacts of the averaging technique that have not been discussed in previous studies.

\subsection{Defining Salinity Anomaly}

In this study, our goal is to track the advection of fresh, arctic-origin water through the boundary current system, identifying predominant pathways and diagnosing their seasonality. To do this, we take advantage of the fact that northern source waters are so much fresher than any other water mass entering the region. In fact, the fresh water advected by the LC can be more than three salinity units fresher than the subtropical water advected by the NAC immediately offshore (Figure 3a). Therefore, we define a salinity anomaly as a function of density that is measured relative to the saltiest water mass that we expect to find within our study domain, Western North Atlantic Central Water (WNACW). We use the standard T-S relationship constructed by Armi and Bray (1982) from observations in the Sargasso Sea 
(Fuglister, 1960; Worthington and Metcalf, 1961) as our standard for WNACW, the end product of advection and mixing between very fresh polar sources and very salty Mediterranean Water (Iselin, 1936; Worthington, 1976; Harvey, 1982; Arhan and King, 1995; McCartney and Maritzen, 2001). The water transported by the NAC will be a modified form of WNACW, ultimately becoming Eastern North Atlantic Central Water (see Section 7). Because we are focused on the northern-source water, which is so much fresher, and not trying to identify more subtle variations in the properties of the NAC, it is sufficient to use the Armi and Bray (1982) curve rather than constructing a more regionalized standard curve.

The salinity anomaly, $S^{\prime}$, is calculated as a function of density at each grid point in our climatology by subtracting the standard salinity at that density from the climatological observations at the same density. As an example, $S^{\prime}$ has been calculated from all of the synoptic hydrographic station data collected along WOCE repeat section AR19, crossing the shelf/slope on the eastern flank of the Grand Banks. Its distribution is shown in Figure 4a relative to the standard curve for WNACW. On the shelf and within the LC the salinity is up to 4.5 units fresher than the standard curve while anomalies within the NAC approach zero offshore. In between these two extremes lies the so-called "Mixed Water" (Soule, 1940; Worthington, 1976) in which intermediate anomalies predominate. Note that there are some observations along AR19 that appear to be even saltier than the standard curve (between $4-10^{\circ} \mathrm{C}$ ). These are most likely remnants of Mediterranean Water that are advected by the NAC. Similar salty anomalies are also observed in synoptic observations in the Gulf Stream (McCartney et al., 1980). To place the extreme freshness of the LC anomalies in perspective, the Lozier et al. (1995) climatology shows that $S^{\prime}$ in the Mediterranean tongue on $\sigma_{0}=27.0$ reaches 0.25 off the Strait of Gibraltar, 
$4000 \mathrm{~km}$ from the Newfoundland Basin. An anomaly of -2.5 in the LC is 10 times this amplitude, and is found $1 / 10$ of the distance from the WNACW carried by the NAC.

In the results to follow, we will present horizontal maps and vertical sections of salinity anomaly calculated from both monthly and annual average climatological fields. The spatial and temporal distribution of the anomaly fields are interpreted in terms of the advection of water mass sources and mixing. In order to track the evolution of fresh shelf water advected by the LC within our study domain, we define a "Shelf Water Layer" whose boundaries are the sea surface and the $\sigma_{0}=26.80$ isopycnal surface. On average, this isopycnal is part of the shelf-slope front (coinciding roughly with the 33.4 isohaline) and grounds near the shelfbreak along the eastern flank of the Grand Banks (Fratantoni and Pickart, 2007). As seen in Figure 4a, variations in salinity anomaly are largest along isopycnal surfaces lighter than $\sigma_{0}=26.80$, where the salinity ranges from very low to very high along a single isopycnal. This is because, lighter isopycnals intersect the very fresh water resident on the shelf. By comparison, the salinity difference is markedly reduced along isopycnals denser than $\sigma_{0}=26.80$ (Figure $4 \mathrm{a}$ ), diminishing to values $\leq$ 0.5 below $\sigma_{0}=27.5(\approx 500 \mathrm{~m}$ depth$)$. Hence, the $\sigma_{0}=26.80$ isopycnal surface lies at the boundary between the very fresh water on the shelf and the much saltier water offshore and at depth, bounding what we call the "Shelf Water Layer" hereafter.

\section{Seasonal Variations in Freshwater}

Strong seasonal variations in salinity have been observed on both the Labrador and Newfoundland Shelves. The seasonal variations are driven by the annual cycle of river discharge and ice-melt onto the shelf and within the adjoining Hudson and Baffin Bays, although identifying a dominant upstream source for the variability has proven difficult (Sutcliffe et al., 
1983, Prinsenberg et al., 1987; Myers et al., 1990; Lazier and Wright, 1993; Schmidt and Send, 2007; Straneo and Saucier, 2008). The freshwater export from Baffin Bay is seasonally concentrated between May and December, peaking in October/November (Cuny et al., 2005). Similarly, the freshest waters are exported from Hudson Strait between June and March with peak freshness occurring in October-December (Straneo and Saucier, 2008). Downstream, on both the Labrador and Newfoundland Shelves, the seasonal cycle of salinity reaches a minimum at progressively later times with increasing depth (Lazier, 1982; Myers et al., 1990; Petrie et al., 1991). Historical observations collected on the Labrador Shelf (Lazier, 1982) indicate that the water at the surface $(200 \mathrm{~m})$ is freshest in July/August (November) and saltiest in Feb/March (May). A long-term monitoring station on the inner Newfoundland Shelf (Station 27; Petrie et al., 1991) shows that the water here is freshest one month later, in September (December) at the surface $(100 \mathrm{~m})$. To summarize, the freshest waters are exported from the Canadian Archipelago onto the northern Labrador Shelf beginning in late spring (May/June), while the peak freshness is observed downstream at progressively later times on the Labrador (July) and Newfoundland (September) Shelves.

Freshwater exiting Davis and Hudson Straits feeds into the LC along the northern Labrador Shelf. Along its southward path, portions of the shelf/slope flow are diverted both onto the shelf and offshore (Figure 5a). Some of these bifurcations result in the export of mass and freshwater from the current while others form temporary branches that re-join the current further downstream. On the seaward side, dynamic topography from some of the oldest surveys in the Grand Banks region indicate that the main branch of the LC bifurcates north of Flemish Cap and near the Tail of the Grand Banks (Figure 5a), leading to export from the shelf (Mathews, 1914; Smith et al., 1937). The transports within the seaward-turning branch north of Flemish Pass have 
not been measured, however observations upstream (Lazier and Wright, 1993) and downstream (Petrie and Buckley, 1996) indicate that the flow through Flemish Pass remains substantial despite the bifurcation near $48^{\circ}-49^{\circ} \mathrm{N}$ ( $\sim 60-90 \%$ of the transport continues south). Our knowledge of the transport partitioning near the Tail of the Grand Banks is also limited. However, observations suggest that only a fraction of the LC transport continues west to the Scotian shelfbreak ( 0.5-1.4 Sv, Loder et al., 2003). There is also current branching onto the shelf (Figure 5a). For instance, a portion of the LC separates from the main shelfbreak current near Hamilton Bank on the Labrador Shelf, forming an inshore branch (Colbourne et al., 1997; Lazier and Wright, 1993; Han et al., 2008). Lazier and Wright (1993) estimate that this inshore branch carries roughly $15 \%$ of the total $11 \mathrm{~Sv}$ of southward transport at this location. Upon reaching the Newfoundland shelf, a portion of the inshore LC turns offshore to re-join the equatorward flow at the shelfbreak (Colbourne et al., 1997), steered by the southward shoaling shelf topography near Flemish Pass, while a smaller branch continues south through Avalon Channel ( 0.4 Sv, Petrie and Anderson, 1983).

If the shelf/slope region is dominated by advection, we should be able to track the propagation of the seasonal freshwater pulse southward along the boundary in the monthly climatology and interpret its spatial variability based on the circulation features described above. Figure $5 \mathrm{~b}$ shows the seasonal progression of the salinity anomaly in the climatology following the shelfbreak from the Labrador Shelf southward to the Tail of the Grand Banks and ending on the southwest side of the Grand Banks (following the heavy black line in Figure 5a). The salinity anomaly has been averaged over the Shelf Water Layer within a $100 \mathrm{~km}$ wide swath centered on the shelfbreak. An annual cycle is evident at all locations north of the Tail of the Grand Banks, with the freshest water arriving in summer/fall and the saltiest water arriving late 
winter. The freshest water is observed in July/August near Hamilton Bank, on the south end of the Labrador Shelf, consistent with the results of Lazier (1982) and with the onset of freshening observed in Hudson and Davis Straits. There is a time lag of 3 months between when the freshest water is observed along the Labrador Shelf and when it is observed east of the Grand Banks in October. The time lag is consistent with the phasing reported by Petrie et al. (1991) for annual salinity variations on the Newfoundland Shelf. The 3-month lag is consistent with an advection speed of $23 \mathrm{~cm} / \mathrm{s}$ along this approximately $1800 \mathrm{~km}$ distance. This is similar to the speeds observed in the LC (Lazier and Wright, 1993), suggesting that, to first order, the signal is advective and not just a phased response to air-sea forcing over the region. In contrast, Houghton and Visbeck (2002) examined the low-passed decadal salinity variability in the LC and found a $2-3 \mathrm{~cm} / \mathrm{s}$ propagation speed, indicating a dominance of local and remote forcing over simple advection at these low frequencies. Similarly slow speeds have been attributed to the propagation of Great Salinity Anomalies in the North Atlantic as well (e.g. Dickson et al., 1988).

The climatology indicates that there are two regions along the shelfbreak where the water is fresher and persists for a longer period than at other locations (Figure 5b). The first is centered at $-500 \mathrm{~km}$ on the distance axis, on the Newfoundland shelfbreak north of Flemish Pass (AugustOctober), and the second is centered at $250 \mathrm{~km}$, along the eastern flank of the Grand Banks south of Flemish Pass (September-November). The freshness of the anomaly in these two locations, relative to upstream anomalies along the shelfbreak, suggests that a portion of this water is most likely advected out to the shelfbreak by the inner-shelf branch of the LC, the inner LC (Figure 5a). On average the freshest water on the Labrador Shelf, derived from both local and upstream sources, is concentrated along the inner shelf in the vicinity of this inshore branch (Lazier, 1982). 
Hence, the freshness of the anomaly at the shelfbreak (Figure 5b) suggests that it arrives via the inshore LC, which converges with the main branch of the LC north of Flemish Pass.

In Figure 5c, we trace the seasonal progression of the salinity anomaly in the climatology along the inshore LC, following the pathway along the thin black line in Figure 5a approximated from drifter observations (Colbourne et al., 1997). During summer, there is a concentration of very fresh water along this path (anomalies exceeding -4), extending southward to roughly -500 $\mathrm{km}$ in Figure $5 \mathrm{c}$ where the shelf topography begins to shoal approaching the Grand Banks (between the white squares in Figure 5a). The fact that the fresh water appears virtually simultaneously at all locations along the northern $700 \mathrm{~km}$ of the inshore path suggests that it does not originate solely in the north, but is dominated by local sources. The temporal broadening of the salinity minimum centered near $-650 \mathrm{~km}$ along this inshore path (Figure $5 \mathrm{c}$ ) suggests that a local fresh water source is "switched on" in July and remains "on" through December. The onset of the local freshening is consistent with the fact that the Labrador Shelf is typically ice-covered through June, finally becoming ice-free by mid-July, and that the local peak freshwater run-off to the shelf occurs in June/July (Petrie et al., 1991). The apparent disappearance of the freshest water along the inshore path immediately downstream of this point (near $-400 \mathrm{~km}$, Figure $5 \mathrm{c}$ ) is symptomatic of the bifurcation in the inshore $\mathrm{LC}$ near $49^{\circ} \mathrm{N}$, where one branch turns offshore to re-join the main LC at the shelfbreak and the other continues southward through Avalon Channel (Figure 5a). Indeed, observations suggest that the freshest water derived from ice-melt and runoff on the Newfoundland and Labrador Shelves eventually arrives downstream in Avalon Channel along this inshore route (Petrie et al., 1991). By contrast, the water that is advected toward the shelfbreak following the offshore branch of the inshore LC in Figure 5a is slightly saltier than the water that remains near the coast (Figure 5c), but it is still fresh enough to explain 
the local minimum observed at the shelfbreak. Likewise, the persistence of the fresh anomaly transported by the inshore LC (-650 km, Figure 5c) explains the persistence of the fresh anomaly observed at the shelfbreak north of Flemish Pass (-500 km, Figure 5b).

The temporal persistence of the minimum salinity anomaly at the shelfbreak north of Flemish Pass $(-500 \mathrm{~km}$, Figure $5 \mathrm{~b})$ is not observed downstream, suggesting that not all of the freshwater arriving at the shelfbreak to the north of Flemish Pass is advected south through the Pass. This may be symptomatic of the bifurcation in the LC that occurs at the shelfbreak near $48^{\circ}-49^{\circ} \mathrm{N}$ (Figure 5a). We see evidence for this pathway in the distribution of salinity anomaly within the Shelf Water Layer calculated from the 100-year mean salinity distribution in our climatology (Figure 4b). In the climatological mean, a tongue of relatively fresh water (low salinity anomaly) extends northward from Flemish Cap along the inshore edge of the Northwest Corner. A modified form of cold/fresh LC water has been observed in synoptic observations as well along the northern edge of the NAC in the Northwest Corner (Lazier, 1994). Note that the Shelf Water Layer in the 100-year mean is outcropped offshore of the shelfbreak along the full length of the Labrador Shelf southward to $49^{\circ} \mathrm{N}$ (Figure $4 \mathrm{~b}$ ). The persistent outcropping limits the cross-shelf exchange of freshwater in the northern domain and suggests that the first offshore pathway available to the LC is encountered immediately north of Flemish Pass, precisely where observations suggest a bifurcation in the current (Figure $4 \mathrm{~b}$ ). This is consistent with the circulation inferred from subsurface floats trajectories (e.g. Lavender et al., 2005) and has been simulated in numerical models (Myers, 2005). Interestingly, sea-ice climatologies (Stroeve and Meier, 2008) and time series observations (http://iup.physik.uni-bremen.de:8084/amsr) consistently show the southern limit of annual sea ice coverage in the western North Atlantic near this bifurcation point (near $47^{\circ} \mathrm{N}$ ). The melting of this advected ice is an additional source 
to continental run-off and precipitation in the Labrador Current, consistent with Petrie et al's. (1991) interpretation of the salinity budget on the Newfoundland Shelf.

The freshwater that is advected south through Flemish Pass is traceable along the eastern flank of the Grand Banks (Figure 5b). However, the minimum salinity anomaly here is fresher and persists longer in time than the anomaly in Flemish Pass. The freshness of the anomaly suggests that it is fed by flow across the Grand Banks. The freshwater on the Grand Banks is primarily derived from the run-off and ice-melt advected by the inner LC (Figure 5a). Observations indicate that the circulation over the broad, shallow areas of the Grand Banks is weak and highly variable (Petrie and Isenor, 1985; Petrie and Anderson, 1983; Greenberg and Petrie, 1988). However, maps of steric height constructed from historical hydrography suggests that the flow is generally southward and that there might be some seasonality to the flow patterns (Petrie and Anderson, 1983; Csanady, 1979). Specifically, the maps indicate that the flow is directed south-eastward across the Grand Banks during a period when the freshest water is arriving in the climatology (July-September; Petrie and Anderson, 1983). The general circulation gives the impression that the persistent delivery of very fresh water in the north gradually spreads south and east across the Grand Banks, eventually encroaching on the shelfbreak region where it may become entrained into the southward flowing LC. We will support this with mapped fields in Section 5.

We trace the seasonality of the cross-shelf distribution of the salinity anomaly in three sections oriented across the shelf at Flemish Cap, east of the Grand Banks, and along the axis of the Newfoundland Ridge at the Tail of the Grand Banks (Figure 6, locations in Figure 5a). The seasonal cycle on the shelf is skewed at all three locations, with the saltiest water observed for a comparatively brief period of time (February-April/May) relative to the arrival and persistence of 
the freshest water (Figure 6). The very broad, shallow nature of the Grand Banks creates a large catchment area that undoubtedly enhances freshness and contributes to the year-round nature of the freshness observed here. The minimum salinity anomaly observed on the shelf in the climatology is equivalent to the anomalies observed in the inshore branch of the LC, suggesting this as its primary source (Figure 5c). The fresh anomaly is observed along the inner- and midshelf in the spring and quickly fills the entire shelf, eventually reaching the shelfbreak along the eastern flank of the Grand Banks in October. These patterns are consistent with the idea that the local minimum observed south of Flemish Pass in Figure 5b most likely results from the flooding of freshwater across the Grand Banks.

To first order, we can track the propagation of the seasonal freshwater pulse along the shelfbreak to the Tail of the Grand Banks. However, downstream (west) of the Tail of the Grand Banks, the temporal pattern is not as smooth and the anomaly is not as fresh as it was east of the Grand Banks (Figure 5b), suggesting that other processes interrupt the clean phasing of freshwater advection along the shelfbreak. This is consistent with the results of Petrie et al. (1991) who speculated that the phasing is interrupted by outflow from the Gulf of St. Lawrence. Another explanation is that a majority of the freshwater at the shelfbreak is advected offshore by the retroflecting LC (Figure 1). The annual cycle at the shelfbreak penetrates offshore in all three cross-shelf sections between Flemish Cap and the Tail of the Grand Banks (Figure 6). At Flemish Cap, the freshwater penetrates well offshore, following the northern bifurcation pathway of the LC (Figures 1 and $4 \mathrm{~b}$ ) and encompassing Flemish Cap during summer when the layer is not outcropped (Figure 6a). East of the Grand Banks, where we expect that retroflected water influences offshore salinities, the fresh water also penetrates onto the slope on a seasonal timescale (Figure 6b). However, while there is a single salinity minimum at the shelfbreak, 
multiple minima appear in the offshore region east of the Grand Banks and at the Tail of the Grand Banks (Figures $6 \mathrm{~b}$ and $6 \mathrm{c}$ ), suggesting that more is going on than simple advection of the freshwater pulse along the retroflection pathway. Furthermore, while there is a clear temporal lag to the arrival of the seasonal pulse of freshwater along the shelfbreak (Figure 5b), the seasonal freshening that is observed over the slope occurs in phase from north to south (Figure 6). In effect the freshest water arrives on the boundary in August/September and is very shortly observed offshore at all locations south of Flemish Cap. Likewise, low salinity water persists offshore for roughly the same period everywhere south of Flemish Cap (June-October).

In addition to looking at the offshore spreading of freshwater at just three locations, we examined its monthly distribution in maps of salinity anomaly averaged over the Shelf Water Layer (the monthly maps are described in detail later). Figure 7 shows the extreme cross-shelf positions of the freshwater boundary defined by $S^{\prime}=-3.0$. This corresponds with the blue/yellow transition in Figures $5 \& 6$ and is representative of salinities ranging from $33.2-33.7$ (Figure 4a). As a reference, we also show the same boundary from the annual mean map (Figure $4 b)$. In general, seasonal excursions in the freshwater boundary are maximized upstream of the Tail of the Grand Banks. In March, the freshwater is confined to the shelf between Flemish Pass and the Tail of the Grand Banks. North of this location, the $\sigma_{0}=26.80$ isopycnal is outcropped. In September, the freshwater boundary is shifted well offshore, so that shelf water encompasses Flemish Cap and the continental slope along the eastern Grand Banks out to the $4000 \mathrm{~m}$ isobath. At its maximum seaward extent the freshwater reaches the inshore edge of the NAC, whose position is estimated based on thermocline topography, specifically where the $\sigma_{0}=27.25$ isopycnal reaches $200 \mathrm{~m}$ depth (Figure 7). 


\section{Retroflection Geometry}

There is a history of thinking that a large portion of the LC retroflects at the Tail of the Grand Banks of Newfoundland, turning offshore and returning north with the comparatively salty NAC. Probably the earliest evidence of this is found in the extensive hydrographic surveys completed by the International Ice Patrol (IIP) beginning in the early 1900s (Smith et al., 1937). Following their description, circulation diagrams typically depict the LC pathway with a single line that parallels the eastern slope of the Grand Banks, curving back toward the north at the Tail of the Grand Banks, suggesting that all of the retroflection occurs in this one location (as shown in Figure 1). This over-simplified pathway is supported by the fact that the LC transport is dramatically reduced (from 6 to $0.5 \mathrm{~Sv}$ ) between Flemish Pass and the Scotian Shelf (Loder et al., 1998) and that a significant portion of the coldest/freshest water disappears from the upper slope between the east and west sides of the Tail of the Grand Banks (Fratantoni and Pickart, 2007). Even the propagation of the seasonal salinity minimum at the shelfbreak appears to break down at the Tail of the Grand Banks (Figure 5b). However, the schematic circulation diagrams and the above evidence all gloss over the details of the retroflection circulation. As commented on by Smith et al. (1937), Voorheis et al. (1973), and by Csanady and Hamilton (1988), maps of dynamic topography indicate that branches of the LC are in fact turned back toward the north at multiple locations between Flemish Cap and the Tail of the Grand Banks. The retroflection is not happening solely at the Tail of the Grand Banks. This aspect of the circulation has also been observed in the trajectories of surface drifters and subsurface floats (Kraus et al., 1987; Carr and Rossby, 2001; Fratantoni, 2001; Niiler et al., 2003; Reverdin et al., 2003; Lavender et al., 2005) and also occurs in numerical models (Han et al., 2008). 
We illustrate the retroflection geometry in our climatology by mapping the depth of the $\sigma_{0}=27.25$ isopycnal (Figure 8a). This density surface is located within the main pycnocline and hence deep enough to be unaffected by seasonal forcing. In the 100-year annual mean the isopycnal surface is uplifted offshore of the Grand Banks, forming a pycnocline ridge that roughly parallels the shelf between Flemish Cap and the Tail of the Grand Banks along the 2500 $\mathrm{m}$ isobath (Figure 8a). Because this pattern is representative of the density structure in the water column above this depth (Figure 9), and because this density surface is well above the zerovelocity reference level for this region (Schott et al, 2004), the depth contours may be considered a proxy for flow streamlines. This is corroborated by the near-linear relationship between dynamic height $(0-1000 \mathrm{~m})$ and the depth of the $\sigma_{0}=27.25$ isopycnal along a cross-shelf section east of the Grand Banks (Figure 8b). This simple interpretation breaks down west of the Tail of the Grand Banks where the pycnocline ridge structure is restricted to shallower depths and where the density distribution is not as vertically coherent (Fratantoni and Pickart, 2007). East of the Grand Banks, the isopycnal topography suggests southward flow along the boundary, turning offshore at the Tail of the Grand Banks and returning northward offshore. This is consistent with the "traditional" retroflection pathway typically depicted in circulation cartoons of this region, including ours in Figure 1. However, there is also a north-south tilt to the pycnocline ridge structure (Figure $8 \&$ 9), with the surface shoaling toward the north indicative of offshore geostrophic shear. While there appears to be a concentration at the Tail of the Grand Banks, this shear distribution suggests that the flow is directed offshore across the full length of the pycnocline ridge crest everywhere south of Flemish Cap.

Vertical sections of mean temperature and salinity oriented across the pycnocline ridge east of the Grand Banks (Figure 8a) show the dramatic property front that exists between the cold, 
fresh polar-origin water flowing south and the warm, salty subtropical water flowing north (Figure 9a). Similarly, vertical sections of salinity oriented along the crest of the pycnocline ridge show that low salinity water occupies the upper $100 \mathrm{~m}$ along the entire length of the ridge between Flemish Cap and the Tail of the Grand Banks in the 100-year climatological average (Figure 9b; section location Figure 8a). The only possible source for this water is the southward flowing boundary current, suggesting that freshwater is advected offshore from the southward to the northward flow regime over the entire region between Flemish Cap and the Tail of the Grand Banks.

In an attempt to quantify the retroflection transport in the climatology, thermal wind fields were calculated from the annual mean fields in Figure 9. The cross-slope section (Figure 9a) coincides with the repeated IIP standard section, A3, while the along-slope section (Figure 9b) is aligned with the crest of the pycnocline ridge (locations Figure 8a). In reality, the depth of the zero velocity line within this region descends from a depth of $1000 \mathrm{~m}$ to the ocean bottom ( $4500 \mathrm{~m})$ over a cross-shore distance of $150 \mathrm{~km}$ (Schott et al., 2004). However, to enable comparison with estimates from earlier studies, here the velocity fields are referenced to zero at $1000 \mathrm{~m}$ across the entire section. At the A3 section, this reference level intersects the steep topography on the continental slope. We follow the method introduced by Helland-Hansen (1934) to extend the thermal wind calculations into shallow water while using a deeper reference level seaward of the shelfbreak. In this method, density surfaces that intersect the bottom topography are extended horizontally through the sediment under the shallower stations, thereby filling bottom triangles while allowing for no flow below the bottom. The same general approach has been used historically for estimating the southward transport of the LC across A3 (Kollmeyer et al., 1967; Petrie and Drinkwater, 1993). 
The thermal wind field at $\mathrm{A} 3$ is characterized by a narrow region of southward flow, centered within $75 \mathrm{~km}$ of the shelfbreak, that is bounded on its seaward side by a broad region of poleward flow (not shown). The velocity distribution captures some portion of both the LC flowing south along the shelf edge and the broader, deep-reaching NAC flowing northward offshore (Figure 8a). The baroclinic transport associated with each of these features in the annual mean climatology is $1.5 \mathrm{~Sv}\left(1 \mathrm{~Sv}=10^{6} \mathrm{~m}^{3} \mathrm{~s}^{-1}\right)$ southward and $17 \mathrm{~Sv}$ northward. For reference, we find that increasing the reference level depth from 1000 to $4500 \mathrm{~m}$ results in only slightly increased equatorward transport within the upper $1000 \mathrm{~m}$ in the LC (1.6 Sv) and more significant changes in the poleward transport associated with the NAC (roughly doubling to $32 \mathrm{~Sv}$ ).

Forty years worth of synoptic IIP surveys crossing the LC at A3 indicate that the geostrophic transport is highly variable here. The reported mean value is $4.1 \mathrm{~Sv}$, more than double our estimate, but with a standard deviation of 2 Sv (Petrie and Buckley, 1996) and a standard error of 0.3 (based on 36 years of data). The horizontal density gradients east of the Grand Banks are concentrated within an extremely narrow band $(\sim 75 \mathrm{~km})$ adjacent to very steep topography. Therefore, the station spacing is critical in order to get an accurate measure of the southward transport even in synoptic measurements. It is possible that some of the synoptic variability reported at $\mathrm{A} 3$ results from variability in the station spacing across this narrow southward flow. Also contributing to the transport variability are variations in the geometry of the pycnocline ridge crest. These variations have been smeared by the averaging process in the construction of our climatological mean section, resulting in weaker cross-slope dynamic height gradients and reduced geostrophic transports compared with synoptic estimates. In fact, the cross-slope distribution of dynamic height associated with the annual mean geometry shown in Figure 9a resembles that observed in synoptic IIP surveys during low transport years (Robe, 1971). 
Finally, as in previous studies, these calculations necessarily neglect the barotropic component of the transport, which may contribute up to $65 \%$ of the total volume transport on the Labrador Shelf (Lazier and Wright, 1993) and up to 80\% in Flemish Pass (Greenberg and Petrie, 1988). Based on the bottom velocities taken from instruments deployed at separate times south of the standard A3 line at water depths of $500 \mathrm{~m}$ (Mountain, 1980) and $1500 \mathrm{~m}$ (Schott et al., 2004), we estimate that an additional 3-7Sv of barotropic transport is possible in the upper $1000 \mathrm{~m}$ (roughly $40-60 \%$ of the total).

Geostrophic velocities relative to $1000 \mathrm{~m}$ are largely south-eastward (offshore) across the annual mean pycnocline ridge section (Figure 9b). Two regions of enhanced offshore velocity coincide with the steeper isopycnal slopes evident in the vertical sections (at 0-150 km and 550$650 \mathrm{~km}$, Figure $9 \mathrm{~b}$ ). The velocity pattern along the ridge (Figure $9 \mathrm{~b}$ ) is reminiscent of the drifter results of Carr and Rossby (2001) showing two of the most probable paths for offshore flow are at roughly these same locations (roughly $42^{\circ} \mathrm{N}$ and $46^{\circ} \mathrm{N}$ ). The total baroclinic transport across the ridge is $4.5 \mathrm{~Sv}$ (above and relative to $1000 \mathrm{~m}$ ), with the largest eastward transport concentrated near the Tail of the Grand Banks and south of Flemish Cap (Figure 9b). This suggests a climatological upper bound on the baroclinic transport through Flemish Pass, amounting to $45-70 \%$ of the total volume transport that others have estimated to be flowing through the Pass (6.3-9.8 Sv, Petrie and Buckley, 1996; 7.6 Sv, Greenberg and Petrie, 1988). This is a larger fraction of the total transport than has previously been attributed to the baroclinic component of the flow, but it also assumes that none of the $4.5 \mathrm{~Sv}$ of eastward flow crossing the ridge is fed by inshore branches of the circulation over the Grand Banks. Additionally, it is possible that part of the LC south of Flemish Pass arrives by flowing east of Flemish Cap, the pathway used by the DWBC (Colbourne and Foote, 2000). Because these waters also may 
retroflect (and indeed are observed flowing north in the NAC), there probably is an additional offshore barotropic component that adds to our baroclinic estimate.

\section{Freshwater Export}

The arrival-time and flushing-rate of the seasonal freshwater pulse, originating as run-off and ice-melt, sets the boundary condition for the freshness of the water exported from the LC along offshore geostrophic advection pathways. Fresh water lies inshore of salty water across the width of the boundary current year-round (Figure 10a). However, as the seasonal freshwater pulse is advected quickly southward by the current, abrupt seasonal transitions in freshness are observed along the shelfbreak (Figure 10b). These transitions are evident in the LC just south of Flemish Pass as the entire current abruptly freshens in March-April and becomes saltier in October-November (Figure 10b). The water carried by the LC is also modified by air-sea fluxes, having large seasonal cycles between strong buoyancy loss in winter, driving convection, and equally strong buoyancy gain in summer, driving restratification (Bunker, 1976). Regionally, the thermal component of the buoyancy forcing dominates the haline component (Schmitt et al., 1989 ) in all four seasons. While seasonal variations in the thermal structure over the Grand Banks are dominated by the air-sea fluxes, not advection (Petrie et al., 1991; Umoh et al., 1995), the variability of the salinity structure is dominated by advection coupled with the seasonal melt of sea ice and continental run-off rather than local E-P fluxes (Petrie et al., 1991).

Seasonally the structure of the pycnocline ridge is robust, although the cross-shore density distribution in the Shelf Water Layer exhibits large seasonal variations in response to surface atmospheric buoyancy forcing (Figure 11). Along the eastern Grand Banks, the ocean experiences a net gain in heat from March-September, peaking in June, followed by a net heat 
loss from October-February, reaching a minimum in January (Bunker, 1976; Umoh et al., 1995). The seasonal pattern of oceanic heating and cooling are related to changes in air temperature, wind speed and wind direction (Bunker, 1976), and we draw on Bunker's assessment of the Grand Banks domain in the following (Umoh et al., 1995 describe similar annual patterns in the relative contributions to the net surface heat flux). Summertime heating results in the formation of a seasonal pycnocline, isopycnally connecting the fresh shelf water in the LC west of the pycnocline ridge with the saltier oceanic water in the northward flow regime east of the ridge (e.g. September, Figure 11). In fall, regional winds veer to westerlies and the air temperature drops below the sea-surface temperature, remaining low throughout the winter (Bunker, 1976). The resulting evaporative cooling and convection removes buoyancy from the Shelf Water Layer and stratification begins to break down (e.g. November, Figure 11). The lightest isopycnals near the surface outcrop first, followed shortly by deeper isopycnals (January, Figure 11) until the entire Shelf Water Layer is outcropped over the pycnocline ridge (March, Figure 11). The convection process is most effective over the pycnocline ridge where the isopycnals are uplifted. The result is that the freshwater is trapped on the shelf inshore of the fully outcropped layer from January to April. By March, the air temperature is warmer than the sea surface temperature, although the return of stratification is slowed by the presence of sea ice which decreases the absorption of solar radiation by the ocean. However, stratification is quickly re-established within the Shelf Water Layer beginning in May when the Grand Banks region is typically icefree and southwesterly winds advect warm moist air over the region (May-July, Figure 11).

Seasonal buoyancy forcing by the atmosphere alters the vertical stratification in the Shelf Water Layer, having the effect of restricting some part, or all, of the cross-ridge geostrophic advection pathways for months at a time by interrupting the continuity of the isopycnals. For 
instance, during summer months restratification extends across the pycnocline ridge, connecting the southward and northward flow regimes and allowing for the export of freshwater at all depths and at all locations within the Shelf Water Layer. However, winter cooling and convection destroys stratification within the Shelf Water Layer, beginning with the lightest isopycnals and most effectively over the pycnocline ridge. Hence, advection across the ridge is blocked for the water along these surfaces beginning in fall. Within a few months, the entire Shelf Water Layer is completely outcropped over the pycnocline ridge and the freshwater in the boundary current is trapped at the shelfbreak.

Seasonal changes in the vertical density distribution in the Shelf Water Layer are lagged over the western North Atlantic. As shown in Figure 12a and b (gray shading), the Shelf Water Layer outcrops first in the north over the Labrador Slope in November. The outcropped region gradually extends southward over Flemish Cap (January) and eventually over the pycnocline ridge east of the Grand Banks (maximally in March, and beginning to retract in April). In concert, freshwater advection pathways vary both vertically (as described above) and horizontally over the domain. Maps of monthly mean salinity anomaly integrated over the Shelf Water Layer illustrate the seasonal evolution of the distribution of freshwater relative to the retroflection geometry south of Flemish Cap (Figure 12a and b). In March, the freshwater boundary (blue) is retracted well inshore of the southward flow regime and the Shelf Water Layer is outcropped (gray shading) along the full length of the pycnocline ridge. In April and May the outcropping region gradually retracts northward along the pycnocline ridge as stratification is re-established in the Shelf Water Layer. At the same time, the freshwater boundary moves offshore to fill in the region of southward shear at the shelfbreak onshore of the pycnocline ridge crest. By May, we see evidence for freshwater advection across the pycnocline 
ridge as (yellow) plumes of freshwater extend across the ridge in three locations. The locations of the plumes are consistent with advection pathways inferred from drifter observations (Carr and Rossby, 2001) and with our interpretation of the distribution of density and salinity in Figure 9b. In May, very fresh water (blue) now encompasses the region of southward shear along the northern pycnocline ridge. In the following months, the time-lagged arrival of fresh shelf water at the boundary is followed by its appearance offshore along the multiple retroflection pathways. During the months of July-October, plumes of very fresh water extend across the pycnocline ridge into the region of northward shear. Particularly strong offshore penetration of freshwater occurs south of $44^{\circ} \mathrm{N}$ in August-September. In November, winter cooling begins to erode the stratification in the Shelf Water Layer and the cross-ridge pathway is blocked for all but the densest (saltiest) portion of the layer (Figure 11). Because this process begins in the north, the layer-integrated salinity anomaly is less fresh along the northern half of the pycnocline ridge during this month (Figure 12b). On the other hand, the winter cooling has not yet begun to impact the stratification further south and the seasonal freshwater pulse at the Tail of the Grand Banks is visible as a fresh tongue protruding offshore and back toward the north (Figure 12b). Cooling continues as the outcropping region creeps southward over the following months, and the cross-ridge advection pathways are gradually restricted (from north to south) to the deepest and saltiest part of the layer, replacing the water over the ridge with a less fresh variety (Figure $12 b)$.

\section{Freshwater fate}

What happens to the freshwater that is advected away from the boundary? Is it advected northward as an identifiable component of the NAC or is it mixed immediately into the large volume of very salty WNACW transported by the NAC? The intermittent formation of 
freshwater filaments and their interleaving with the NAC are not distinguishable in a climatology. For this reason, we return to the original historical station data in order to look for evidence that fresh LC water returns north within the western edge of the NAC. We assembled all available historical station data that were collected after 1950 within a 1-degree box centered on the standard IIP line, A3 (location in Figure 8a). Assuming once again that the depth field in Figure 8a is a proxy for flow streamlines east of the Grand Banks, the station data were binned in geographic strips paralleling these isopycnal depth contours. By grouping the observations in this way, and assuming a frozen flow field, we separate the observations falling within the LC from those that fall within the offshore-adjacent band of poleward shear associated with the retroflected LC and the onshore part of the NAC (Figure 8a). Within each strip, we calculate the percentage of the water samples in the Shelf Water Layer that contain one of three varieties of water based on the salinity anomaly of the sample. Fresh, mixed and salty classes are defined by $S^{\prime}<=-3,-3<S^{\prime}<=-2$, and $S^{\prime}>-2$, respectively (Figure 4), delimiting samples containing fresh LC water, intermediate anomalies, and diluted NAC water. The intermediate anomalies can reflect actual physical mixture of those two waters, but more typically have origins in the lower part of the LC layer where run-off has less influence on the salinity and $S$ ' is inherently less negative.

Looking at the statistics of the full 50-year collection of samples (gray shaded curves, Figure 13), we find that $60-80 \%$ of samples inshore of the mean retroflection axis (in the LC domain) contain the freshest water class (Figure 13a), while the remaining 20-35\% are associated with intermediate anomalies (Figure 13b) and less than 5\% with the saltiest class (Figure 13c). By contrast, the number of samples containing the saltiest anomalies grows with distance offshore of the retroflection axis, reaching $50 \%$ occurrence roughly $130 \mathrm{~km}$ offshore of the axis (Figure 13c). At the same point, the freshest water class is still found in more than $25 \%$ of the samples 
over this same distance. This indicates that fresh $\mathrm{LC}$ water is identifiable along the inshore edge of the NAC in the Shelf Water Layer, and we can expect to find the largest volume of this water concentrated within the inshore $130 \mathrm{~km}$ of the northward flow within this layer. For reference, we estimate that the core of the NAC is located approximately $300 \mathrm{~km}$ from the retroflection axis in Figure 13, based on the $12^{\circ} \mathrm{C}$ isotherm reaching $400 \mathrm{~m}$ depth. This position is also shown for reference in Figure 8a.

The statistics compiled from seasonal subsets of the historical samples (colored curves, Figure 13) show the synoptic origins of the observed climatological seasonal freshwater distributions. Within the LC, inshore of the retroflection axis, summer (August-October) saw the largest fraction of samples containing the freshest water while winter (February-April) saw the smallest (Figure 13a). This is consistent with the timing associated with the advection of the seasonal freshwater pulse along the boundary (Figure 5b). Offshore of the retroflection axis, the number of samples containing the freshest water is elevated relative to the long-term statistics in spring (May-July) and summer (Figure 13a). The occurrence of the freshest class drops from summer to fall within the LC, while the number of samples having intermediate freshness increases (Figure 13b). This fluctuation between fresh and intermediate salinity classes captures the changing boundary condition determining the freshness of the water that is ultimately exported from the LC to the deep ocean, as well as the effect of the buoyancy removal through the fall. This is consistent with our inference that freshwater is advected offshore only along isopycnal surfaces that are not yet outcropped. In fact, in fall (November-January) the elevated occurrence of the freshest class is limited to a $50 \mathrm{~km}$ band just offshore of the retroflection axis, presumably as the last of the very fresh water is advected offshore at the Tail of the Banks before winter cooling completely destroys the stratification in the south (e.g. Figure 12b). By winter, 
the number of samples containing the saltiest water class is elevated everywhere offshore of the retroflection axis and the water at the axis is largely of intermediate freshness (Figure 13b).

The statistics derived from the historical station data give an estimate for the offshore influence of fresh LC water in the NAC which we can relate to an independent estimate of the LC circulation from mass and salt conservation in the climatology. We do this following two separate approaches. In the first, we use the geostrophic estimate of the retroflection transport crossing the pycnocline ridge (Figure 9b), and its known salinity, to estimate the width over which we would expect to find LC transport to be distributed within the northward flow. If just mass conservation were required, the width would be determined by the position where the accumulated transport equals the incoming retroflected transport. However, since the retroflected water is diluted by some portion of NAC transport as it returns north, salt conservation requires that $\mathrm{LC}$ water must be intermingled with the NAC further offshore than mass conservation would imply. In the second approach, we invert the problem, treating the retroflection transport as the unknown. In this method we partition the estimated northward transport offshore of the retroflection axis (Figure 9a) into LC and NAC contributions based on the departure of the observed salinity from the "pure" salinity of fresh LC water and salty WNACW. This method gives a larger transport than the former because it attributes all of the fresh aspects of the northward flow to admixture of LC waters. By contrast, the first method isolates the fraction of the northward flow that transports the same freshness as that prescribed for the retroflecting LC, and any additional northward fresh transport is ignored.

\subsection{LC Width of Influence}

In the first method, we use the annual mean distribution of salinity from the climatology and the calculated geostrophic transport across A3 to estimate what portion of the northward flow, 
crossing A3, contains retroflected LC water. The observed northward transport across A3 is fed by the total LC transport retroflected south of A3 plus the transport of the NAC so that

$$
Q_{L C}+Q_{N A C}=\sum_{i} Q_{c \lim _{i}}
$$

where $Q_{N A C}$ and $Q_{L C}$ are the total geostrophic transport of the NAC and retroflected LC and $Q_{c \lim i}$ is the increment of observed transport flowing through a single $20 \mathrm{~km}$ bin $(i)$ across the northward flow regime at A3. At the same time, the total observed salinity flux across A3 is derived from the sum of relatively fresh water transported by the retroflecting LC and comparatively salty water transported by the NAC, so that:

$$
Q_{L C} \times S_{L C}+Q_{N A C} \times S_{N A C}=\sum_{i} Q_{c \lim _{i}} \cdot S_{c \lim _{i}}
$$

where $S_{L C}$ and $S_{N A C}$ are the average salinity of the LC and NAC respectively, and $S_{c \lim i}$ is the observed layer-averaged salinity in the climatology within a single cross-slope bin $(i)$ across the northward flow regime at A3. By searching for the distance at which these two conservation equations are satisfied, we can estimate the width of the belt in which the LC waters recirculate north.

All variables are estimated within the upper layer, bounded at depth by the $\sigma_{0}=27.25$ isopycnal. As shown previously, the topography of this isopycnal is representative of dynamic topography in the upper $1000 \mathrm{~m}$ (Figure $8 \mathrm{~b}$ ) and is deep enough to be unaffected by seasonal forcing. We assume $Q_{L C}=1.4 \mathrm{~Sv}$ because it is the portion of the offshore transport that crosses the pycnocline ridge crest south of A3 within the upper layer of our climatology (Figure 9b). We estimate this quantity from the along-ridge section (Figure 9b) rather than the cross-ridge section (Figure 9a) in order to avoid the sampling issues and reference velocity assumptions that 
complicate transport calculations near steep topography (recall that the equatorward transport of the LC estimated in our climatology is small for this reason.) We estimate $S_{L C}=33.15$ is the average salinity of this retroflected water, as it is the annual average salinity observed inshore of the retroflection ridge axis at A3 (Figure 9a). Similarly, $S_{N A C}=35.5$ is the layer-averaged salinity found at the offshore limit of A3 in the climatology and we consider this "pure" NAC water. Marching offshore along A3 from the axis of the retroflection ridge crest (the origin in Figure $9 \mathrm{a}$ ), we find that the two equations are satisfied roughly $160 \mathrm{~km}$ offshore of the axis into the northward flow (Figure 14). Hence, while mass conservation alone suggests that all $1.4 \mathrm{~Sv}$ of LC water could be accounted for within the first $90 \mathrm{~km}$, that water is saltier than the LC water that has been retroflected. Salt conservation dictates that, instead, LC water is spread over a larger distance within this layer and mingled with roughly an equal amount of NAC water $(\sim 1.2$ $\mathrm{Sv})$. The width of influence from this climatological estimate $(160 \mathrm{~km})$ is consistent with the width inferred from the statistics of the historical station data $(130 \mathrm{~km})$, and is approximately half of the distance to the core of the NAC (estimated to be $300 \mathrm{~km}$ offshore of the retroflection axis).

\subsection{Transport Partitioning in the Northward Flow}

In the previous calculation we estimated that $1.4 \mathrm{~Sv}$ crosses the retroflection ridge south of A3 to enter the northward flow regime. However, we actually do not know what fraction of the LC retroflects into the NAC. By rearranging the algebra in Eqs. (1) and (2), we can diagnose $Q_{L C}$, asking how much transport is required to balance the mass and salt distribution observed in the northward limb of the retroflection in the climatology. 
By rewriting Eq. (1) as $Q_{N A C_{i}}=Q_{c \lim _{i}}-Q_{L C_{i}}$, and substituting into Eq. (2) we can solve for $Q_{L C}$, giving

$$
Q_{L C_{i}}=Q_{c \lim _{i}}\left[\frac{S_{c \lim _{i}}-S_{N A C_{i}}}{S_{L C_{i}}-S_{N A C_{i}}}\right]
$$

Again, all variables are estimated within the upper layer, bounded at depth by the $\sigma_{0}=27.25$ isopycnal. Here, $S_{N A C}$ is the standard salinity of "pure" WNACW advected by the NAC at a single cross-shore position within the northward return flow. We use the annual mean density distribution along A3 and the standard Armi \& Bray (1982) curve to approximate the distribution of $S_{N A C}$ along A3 (Figure 15a). Hence, the numerator in (3) is a measure of the freshness of the observed salinity at each point relative to "pure" WNACW. As before, $S_{L C}$ is the average salinity of the retroflected LC water. Therefore, the bracketed term in (3) is a measure of the fraction of water at a given location in the northward flow that originated in the LC. This ratio is shown in Figure 15b (black curve) and gives the fraction of the transport at a single point that is attributable to $\mathrm{LC}$ water, ranging from $85 \%$ at the retroflection axis to $15 \%$ at the NAC axis. By comparison, the percent occurrence of LC water in historical station data (the combined occurrence of the fresh and intermediate classes in Figure 13) shows a very similar trend (Figure 15b). This ratio does not go to zero at the core of the NAC because the NAC is actually carrying a modified form of pure WNACW. In this simple model, we have made no attempt to differentiate between strong LC influences and weaker slopewater influences. Because we have neglected the influence of slopewater in this calculation, our $Q_{L C_{i}}$ is an upper bound on the transport. 
The cumulative sum of $Q_{L C_{i}}$ over the northward flow regime represents the total LC transport across the section that can account for the observed dilution relative to the standard salinity in the climatology. We find that this transport is no higher than $2.6 \mathrm{~Sv}$ and increases almost linearly with offshore distance until reaching the core of the NAC at $300 \mathrm{~km}$ (Figure 15c). Offshore of this point, the layer-averaged salinity increases (Figure 15a), approaching the standard WNACW curve, as does the northward transport of the NAC (Figure 15c). Based on a collection of synoptic IIP surveys (Robe, 1971), we estimate that the LC transports between 0.5-2.7 Sv of the average 4.1 Sv southward in the upper layer $\left(\sigma_{0} \leq 27.25\right)$ at A3. Our estimate that $2.6 \mathrm{~Sv}$ of the northward flow crossing A3 in the climatology is attributable to LC water is comparable to the upper bound on these synoptic estimates, implying that most of the estimated equatorward LC transport at the boundary retroflects back toward the north. This is consistent with the earlier cited estimates of only a very weak shelf/slope transport west of the Tail of the Grand Banks. Upon expulsion we anticipate that much of the freshwater intermingles with and is dispersed by the larger NAC transport, although the fresh anomalies are still identifiable within the inshore edge of the NAC in synoptic station data at A3. This result is corroborated by the synoptic hydrography along WOCE repeat line AR19, crossing the retroflection region immediately south of line A3. Here, fresh anomalies with magnitudes up to 3 salinity units fresher than WNACW are found embedded within the inner edge of the northward flow of the NAC (Figure 16). For a section view of filaments of retroflected LC water flowing north, see Krauss et al. (1987 and 1990) and Kieke et al. (2009). An earlier view by La Violette (1981) included satellite SST imagery of the filaments simultaneous with ship profile descriptions of signatures down to 1500 $\mathrm{m}$. 
The nature of our data precludes considering the effects of seasonal variations in the strength of the LC and its retroflection. While we find that the retroflection ridge geometry is robust, it should be noted that large seasonal changes in the density structure within the upper few hundred meters can lead to significant seasonal variability in the LC transport. Lazier and Wright (1993) report that the $\mathrm{LC}$ transport at Hamilton Bank varies seasonally by up to $4 \mathrm{~Sv}$, relative to a mean of $11 \mathrm{~Sv}$, peaking in October and becoming weakest in March-April. Fischer et al. (2004) report a similar seasonal phasing for the velocity at the only instrument in their DWBC array at $53 \mathrm{~N}$ that sampled the edge of the LC. There is also evidence that the LC transport can vary significantly on inter-annual timescales and that these fluctuations may be correlated with greater penetration of cold/fresh LC water west of the Tail of the Grand Banks (Petrie and Drinkwater, 1993). However the impact of such fluctuations on the geometry of the retroflection and its transport partitioning remains unknown.

\section{Discussion}

In this study 100 years of historical hydrographic data have been used to describe the seasonal variations and annual mean pattern of freshwater pathways along and across the shelf/slope boundary in the western North Atlantic. We have paid particular attention to the current branching that occurs at the Tail of the Grand Banks of Newfoundland as this has long been identified as a preferential region for the loss of mass and freshwater from the boundary. The climatology suggests that, while cold/fresh northern-source waters are advected offshore within the retroflecting LC at the Tail of the Grand Banks, this is not the only export pathway for these waters to reach the interior North Atlantic. Dynamic topography suggests that freshwater is advected offshore along the full length of the boundary between Flemish Cap and the Tail of the Grand Banks, amounting to a progressive retroflection of most of the LC over this distance. 
This dynamical evidence is supported by salinity anomaly maps that show the time-lagged arrival of fresh shelf water at the boundary, followed by its appearance offshore. There is direct evidence in synoptic station data that the fresh retroflected LC water returns north as an identifiable component of the western NAC. Several factors combine to produce the patterns of freshwater distribution that we have observed across the retroflection region south of Flemish Cap: (1) the arrival and flushing-rate of the seasonal freshwater pulse, originating as run-off and ice-melt, sets the boundary condition for freshwater export, (2) seasonal buoyancy forcing at the surface alters the vertical stratification, seasonally restricting certain export pathways, and (3) the density structure along the eastern Grand Banks defines an offshore geostrophic shear for the upper $1000 \mathrm{~m}$ that joins streamlines in the southward LC with the northward flow farther offshore, defining the progressive retroflection of the LC.

Why does the LC retroflect? On basin scales, the Grand Banks of Newfoundland is recognized as a critical location (e.g. Rossby, 1999), as it is here that the western boundary currents from the subtropical gyre (the Gulf Stream) and subpolar gyre (the LC) meet. The western boundary current regime in the central subpolar gyre extends vertically from the shelf to the abyss, including the LC and the Deep Western Boundary Current (Lazier and Wright, 1993; Fischer et al., 2004). The same order of transports and vertical structure are also observed east of the Grand Banks (Meinen, 2001; Schott et al., 2004). The wind stress curl extends obliquely across the North Atlantic from $42^{\circ} \mathrm{N}$ at the Tail of the Grand Banks to $50^{\circ} \mathrm{N}$ near Ireland. Depending on the wind climatology, the inter-gyre boundary intersects the western boundary between $48^{\circ}$ and $50^{\circ} \mathrm{N}$ (Townsend et al., 2000). The western boundary current in the subtropical gyre overshoots this inter-gyre boundary, with the NAC looping north to $51^{\circ}-52^{\circ} \mathrm{N}$ in the socalled Northwest Corner (Worthington, 1976; Lazier, 1994). Likewise, the LC overshoots the 
inter-gyre boundary in the subpolar gyre, looping south to $42^{\circ} \mathrm{N}$. Hence, the LC retroflection and the corresponding deeper elements in the retroflecting Deep Western Boundary Current could represent a distorted closure of the subpolar gyre: a Southwest Corner for the subpolar gyre complementing the Northwest Corner overshoot of the subtropical gyre. That said, there is no definitive explanation for the LC retroflection as of yet. Clearly, the topography of the Grand Banks plays a role in shaping the LC retroflection - for example, the disappearance of the boundary at $43^{\circ} \mathrm{N}$ due to the westward turn of the shelfbreak, and the substantial deep circulation barrier of the SE Newfoundland Ridge. What is clear is that the mix of local dynamics can not be separated from the influences of the basin-scale circulation. Chapman (2003) modeled the dynamics of an idealized shelfbreak current as it encounters a sharp topographic bend, and argued that the topography and ambient flow fields in the vicinity of the Grand Banks make it likely that buoyant Labrador Shelf water will leave the boundary at this location. However, his results are not only dependent on the shelf geometry but also on the prescription of the alongshore flow on the open boundary to the interior ocean.

The LC is one component of a much larger interconnected shelf/slope current system that advects cold/fresh subpolar and arctic-origin water equatorward. The large-scale boundary current is fed by the export of freshwater from the arctic through Denmark Strait, Davis Strait, and Hudson Strait and by the accumulation of coastal discharge along the length of the subpolar continental shelf, including the annual run-off and melt from the Greenland ice sheet. Together with the Deep Western Boundary Current, the shelf-slope current represents the cold/fresh half of the northern AMOC and is an important conduit for the communication of climate variability away from its source. The other half of the northern AMOC involves the poleward advection of warm/salty subtropical waters by the NAC and its extension into the eastern North Atlantic. The 
cold/fresh and warm/salty limbs come into direct contact east of the Grand Banks of Newfoundland where large amounts of mass and freshwater leave the boundary to become entrained in the western edge of the NAC. The freshening that is imparted to the NAC at the Tail of the Grand Banks contributes to the cooling and freshening of the northward flowing subtropical waters and their subsequent transformation in the Arctic basin.

Future freshening of water exported from the Arctic is often described as a critical threat to the functionality of the AMOC. Model simulations suggest that, if enough freshwater were to be introduced into convective regions in the North Atlantic, the AMOC would be disrupted or could even shut down completely (Manabe and Stouffer, 1997; Renssen et al., 2002). However, most of the model studies that have been designed to look at the response of the AMOC to fresh water anomalies are too coarse to resolve the shelf topography or boundary currents that govern freshwater advection pathways. The most significant freshwater input to the North Atlantic is derived from river discharges into the Arctic and the delivery of that directly into the shelf-slope current in the North Atlantic, further augmented by run-off from Greenland and northern North America. By extension, the boundary currents play a critical role in determining where and how much of this freshwater enters the interior gyres in the North Atlantic.

Our results suggest that most of the transport loss on the western boundary is concentrated between Flemish Cap and the Tail of the Grand Banks, well downstream of the convection regions in the Labrador Sea. This is consistent with Myers (2005), whose model results suggest that there is little exchange between the Labrador Shelf and the interior. Similarly, Schmidt and Send (2007) were unable to show a significant connection between the annual cycle of freshening in the central Labrador Sea and that observed on the Labrador Shelf, finding a more significant connection with the West Greenland Shelf. In a climatological mean sense, our 
results suggest that the fresh shelf water leaving the boundary near the Tail of the Grand Banks has a surprisingly low impact outside the boundary current itself, a direct consequence of the fact that it leaves the boundary and immediately encounters the NAC. Our analysis suggests that fresh retroflected LC water does not arrive unmodified in the interior of the subpolar gyre (the hosing concept), but rather it is strained out into filaments and dissipated by lateral mixing. Indeed, this is implicit in considering how one creates and maintains the eastern Central Water properties in the NAC thermocline through a lateral mixing balance between saline Mediterranean water and fresh subpolar water (Harvey, 1982; Arhan and King, 1995; Mauritzen et al., 2001).

Of course, perturbations in the volume or freshness of discharge may alter the mean dynamics, shifting export pathways or adding new ones so that they may impact deep water convection in the subpolar North Atlantic. Considering the results of Schmidt and Send (2007) the impact may be significantly different depending on where the freshwater anomaly enters the boundary current system (e.g. onto the Greenland or Labrador Shelf). For instance, an anomalous freshwater pulse in the West Greenland Current (derived from increased Greenland ice-melt or fresh water export through Denmark Strait) may have a direct impact on the central Labrador Sea through the efficient eddy processes at work along the west Greenland Shelf (Schmidt and Send, 2007). In contrast, Myers (2005) predicts that even a significant increase in freshwater export from the Canadian Arctic through Davis Strait will remain near the boundary along the length of the Labrador Shelf. Given these circulation constraints, and the fact that the NAC transports roughly 14 times the volume of much saltier water (3-5 units saltier) than the LC where it eventually leaves the boundary, it is difficult to imagine a scenario in which even a very large freshwater anomaly would arrive unmodified in the interior. 
Acknowledgements: We are thankful for the guidance provided by Ruth Curry in the implementation of HydroBase techniques to this analysis. This work was supported by a grant from the Woods Hole Oceanographic Institution's Ocean and Climate Change Institute (PF) and by the National Science Foundation under grant OCE-0550423 (PF and MM). 
Armi, L., and N. A. Bray, 1982. A standard analytic curve of Potential Temperature versus Salinity for the Western North Atlantic. J. Phys. Ocean., 12, 384-387.

Arhan, M. and B. King, 1995. Lateral mixing of the Mediterranean Water in the eastern North Atlantic. Journal of Marine Research, 53, 865-895.

Bunker, A. F., 1976. Computations of surface energy flux and annual air-sea interaction cycles of the North Atlantic Ocean. Monthly Weather Review, 104, 1122-1140.

Carr, M-E., and H. T. Rossby, 2001. Pathways of the North Atlantic Current from surface drifters and subsurface floats. J. Geophys. Res., 106(3), 4405-4419.

Chapman, D. C., 2003. Separation of an Advectively trapped buoyancy current at a bathymetric bend. JPO, 33, 1108-1121.

Chapman, D. C., and R. C. Beardsley, 1989. On the origin of shelf water in the Middle Atlantic Bight. J. Phys. Oceanogr., 19, 384-391.

Colbourne E., B. deYoung, S. Narayanan, and J. Helbig, 1997. Comparison of hydrography and circulation on the Newfoundland Shelf during 1990-1993 with the long-term mean. Can. J. Fish. Aquat. Sci., 54, 68-80.

Colbourne, E., and K. D. Foote, 2000. Variability of the stratification and circulation on the Flemish Cap during the decades of the 1950s-1990s. J. Northw. Atl. Fish. Sci., 26, 103-122.

Condron, A., P. Winsor, C. Hill, and D. Menemenlis, 2009. Simulated response of the Arctic freshwater budget to extreme NAO wind forcing. Journal of Climate, 22(9), doi:

10.1175/2008JCLI2626.1

Csanady, G. T., 1979. The pressure field along the western margin of the North Atlantic. J. Geophys. Res., 84, 4905-4915.

Csanady, G. T., and P. Hamilton, 1988. Circulation of slopewater. Cont. Shelf Res., 8, 565-624.

Curry, R. G., 1996. HydroBase: A database of hydrographic stations and tools for climatological analysis. Woods Hole Oceanographic Institution Technical Report, WHOI-96-01, $44 \mathrm{pp}$.

Cuny, J., P. B. Rhines, R. Kwok, 2005. Davis Strait volume, freshwater and heat fluxes. DeepSea Research I, 52, 519-542.

Dickson, R. R., J. Meincke, S.-A. Malmberg, and A. J. Lee, 1988. The "Great Salinity Anomaly" in thenorthern North Atlantic, 1968-1982. Prog. Oceanogr., 20, 103-151.

Fischer J., F. A. Schott, and M. Dengler, 2004. Boundary circulation at the exit of the Labrador Sea. J. Phys. Oceanogr., 34, 1548-1570.

Fratantoni, D. M., 2001: North Atlantic surface circulation during the 1990's observed with satellite-tracked drifters. Journal of Geophysical Research, 106, 22067-22093. 
Fratantoni and Pickart, 2007. The western North Atlantic shelfbreak current system in summer. Journal of Physical Oceanography, 37, 2509-2533.

Fuglister, F. C., 1960. Atlantic Ocean Atlas of temperature and salinity profiles and data from the IGY of 1957-1958. Woods Hole Oceanographic Institution Atlas Series, 1, 209 pp.

Greenberg D. A., and B. D. Petrie, 1988. The mean barotropic circulation on the Newfoundland shelf and slope. J. Geophys. Res., 93, 15,541-15,550.

Han, G., Z. Lu, Z. Wang, J. Helbig, N. Chen, and B. de Young, 2008. Seasonal variability of the Labrador Current and shelf circulation off Newfoundland. J. Geophys. Research, 113, C10013, doi:10.1029/2007JC004376.

Harvey, J. H., 1982. Q-S relationships and water masses in the eastern North Atlantic. Deep-Sea Research, 29, 1021 - 1033.

Helland-Hansen, B., 1934. The Sognefjord Section. oceanographic observations in the northernmost part of the North Sea and the southern part of the Norwegian Sea. In James Johnstone Memorial Volume, University Press of Liverpool, UK, pages 257-274.

Houghton, R. W. and M. H. Visbeck, 2002. Quasi-decadal salinity fluctuations in the Labrador Sea. J. Physical Oceanography, 32, 687-701.

Iselin, C. O. D., 1936. A study of the circulation of the western North Atlantic. Pap. Physical Oceanography, 4(4), 101.

Keigwin L. D., J. Sachs, Y. Rosenthal, and E. A. Boyle, 2005. The 8200 year B. P. event in the slope water system, western subpolar North Atlantic, Paleoceanography, 20, doi:10.1029/2004PA001074.

Kieke, D., B. Klein, L. Stramma, M. Rhein, and K. P. Koltermann, 2009. Variability and propagation of Labrador Sea Water in the southern subpolar North Atlantic. Deep Sea Research I, doi: 10.1016/j.dsr.2009.05.010.

Kollmeyer R. C., D. A. McGill, and N. Corwin, 1967. Oceanography of the Labrador Sea in the vicinity of Hudson Strait in 1965. U.S. Coast Guard Oceanographic Report No. 12, CG 373-12, $104 \mathrm{pp}$.

Krauss, W., E. Fahrbach, A. Aitsam, J. Elken, and P. Koske, 1987: The North Atlantic current and its associated eddy field southeast of Flemish Cap. Deep-Sea Research Part A.

Oceanographic Research Papers, 34, 1163-1185.

Krauss, W., R. H. Käse, and H.-H. Hinrichsen, 1990: The branching of the Gulf Stream southeast of the Grand Banks. Journal of Geophysical Research, 95, 13089 - 13103.

Kulan, N. and P. G. Myers, 2009. Comparing two climatologies of the Labrador Sea: Geopotential and isopycnal. Atmosphere-Ocean, 47(1), 19-39.

La Violette, P. E., 1981: Variations in the frontal structure of the Southern Grand Banks. Vol. 87, NORDA Technical note, NSTL Station, iii, 48pp. 
Lavender, K., W. B. Owens, and R. Davis, 2005: The mid-depth circulation of the subpolar North Atlantic Ocean as measured by subsurface floats. Deep Sea Research I, 52, 767-785.

Lazier, J. R. N., 1982. Seasonal variability of temperature and salinity in the Labrador Current, J. Mar. Res., 40, Supplement, 341-356.

Lazier, J. R. N., 1994. Observations in the Northwest Corner of the North Atlantic Current. J. Phys. Oceanogr., 24, 1449-1463.

Lazier J. R. N., and D. G. Wright, 1993. Annual velocity variations in the Labrador Current, J. Phys. Oceanogr., 23, 659-678.

Loder J. W., B. Petrie, and G. Gawarkiewicz, 1998. The coastal ocean off northeastern North America. A large-scale view. in The Sea, A. R. Robinson and K. H. Brink, Eds., 105-133 pp.

Loder, J. W., C. G. Hannah, B. D. Petrie, and E. A. Gonzalez, 2003. Hydrographic and transport variability on the Halifax section. J. Geophys. Res., 108, 8003, doi:10.1029/2001JC001267.

Lozier, M. S., M. S. McCartney, and W. B. Owens, 1994. Anomalous anomalies in averaged hydrographic data. J. Physical Ocean., 24, 2624-2638.

Lozier, M. S., W. B. Owens, and R. G. Curry, 1995. The climatology of the North Atlantic. Prog. Oceanog., 36, 1-44.

Manabe, S., and R. J. Stouffer, 1997. Coupled ocean-atmosphere model response to freshwater input: Comparison to Younger Dryas event, Paleoceanography, 12, 321-336.

Mathews, D. J., 1914. Report on the work carried out by the S. S. Scotia, 1913. Ice observation, meteorology, and oceanography in the North Atlantic Ocean. Darling and Son. Publ., London.

Mauritzen, C., Y. Morel, and J. Paillet, 2001. On the influence of Mediterranean Water on the Central Waters of the North Atlantic Ocean. Deep-Sea Research Part I: Oceanographic Research Papers, 48, 347-381.

McCartney, M. S., L. V. Worthington, and M. E. Raymer, 1980. Anomalous water mass distributions at 55W in the North Atlantic in 1977. Journal of Marine Research, 38(1), 147-172.

McCartney, M. S. and C. Mauritzen, 2001. On the origin of the warm inflow to the Nordic Seas. Progress In Oceanography, 51, 125-214.

Meinen, C. S., 2001. Structure of the North Atlantic current in stream-coordinates and the circulation in the Newfoundland Basin. Deep-Sea Research Part I: Oceanographic Research Papers, 48, 1553-1580.

Mikhailov, N. N., E. D. Vyazilov, V. I. Lomonov, N. S. Studyonov, and M. Z. Shairmardonov, 2002. Marine Expeditionary Investigations of the World Ocean. World Data Center for Oceanography, International Ocean Atlas and Information Series, Vol 5, NOAA Atlas NESDIS 56, R. Tatusko and S. Levitus, Eds., National Oceanographic Data Center. 
Mountain, D. G., 1980. Direct measurements in the Labrador Current. J. Geophys. Research, 85(7), 4097-4100.

Myers, R. A., 2005. Impact of freshwater from the Canadian Arctic Archipelago on Labrador Sea Water formation. Geophysical Research Letters, 32, L06605, doi:10.1029/2004GL022082.

Myers, R. A., R. A., Akenhead, and K. F. Drinkwater, 1990. The influence of Hudson Bay runoff and sea-ice melt on the salinity of the inner Newfoundland shelf. Atmospheric-Oceans, $28,241-256$.

Niiler, P. P., N. A. Maximenko, and J. C. McWilliams, 2003: Dynamically balanced absolute sea level of the global ocean derived from near-surface velocity observations. Geophysical Research Letters, 30, 4.

Petrie B., and C. Anderson, 1983. Circulation on the Newfoundland continental shelf. Atmos. Ocean., 21, 207-226.

Petrie, B. and A. Isenor, 1985. The near-surface circulation and exchange in the Newfoundland Grand Banks region. Atmosphere-Ocean, 23(3), 209-227.

Petrie B., J. W. Loder, S. Akenhead, and J. Lazier, 1991. Temperature and salinity variability on the eastern Newfoundland Shelf: The annual harmonic. Atmosphere-Ocean, 29(1), 14-36.

Petrie B., J. W. Loder, J. Lazier, and S. Akenhead, 1992. Temperature and salinity variability on the eastern Newfoundland Shelf: The residual field. Atmosphere-Ocean, 30(1), 120-139.

Petrie, B., and K. Drinkwater, 1993. Temperature and salinity variability on the Scotian Shelf and in the Gulf of Maine 1945-1990. J. Geophys. Res., 98, 20 079-20 089.

Petrie, B., and J. Buckley, 1996. Volume and freshwater transport of the Labrador Current in Flemish Pass. J. Geophys. Res., 101, 28335 - 28342.

Prinsenberg S. J., R. H. Loucks, R. E. Smith, and R. W. Trites, 1987. Hudson Bay and Ungava Bay runoff cycles for the period 1963 to 1983. Can. Tech. Rep. Hydrogr. Ocean Sci., 92 (viii), $71 \mathrm{pp}$.

Renssen H., H. Goosse, and T. Fichefet, 2002. Modeling the effect of freshwater pulses on the early Holocene climate: The influence of high-frequency climate variability. Paleoceanography, 17, Art. No. 1020.

Reverdin, G., P. P. Niiler, and H. Valdimarsson, 2003: North Atlantic Ocean surface currents. Journal of Geophysical Research C: Oceans, 108, 2-21.

Robe, R. Q., 1971. Oceanographic observations North Atlantic standard monitoring sections A1, A2, A3, and A4 1967-1968. U.S. Coast Guard Oceanographic Report No. 43, CG 373-43, 227 pp.

Rossby, T., 1999. On gyre interactions. Deep-Sea Research Part II: Topical Studies in Oceanography, 46, 139-164. 
Schmidt, S. and U. Send, 2007. Origin and composition of seasonal Labrador Sea freshwater. Journal of Physical Oceanography, 37, 1445-1454.

Schmitt, R. W., P. S. Bogden, and C. E. Dorman, 1989. Evaporation minus precipitation and density fluxes for the North Atlantic. J. Phys. Ocean., 19, 1208-1221.

Schott, F. A., R. Zantopp, L. Stramma, M. Dengler, J. Fischer, and M. Wibaux, 2004. Circulation and deep-water export at the western exit of the subpolar North Atlantic. J. Phys. Ocean., 34, 817-843.

Smith E. H., F. M. Soule, and O. Mosby, 1937. The Marion and General Greene Expeditions to Davis Strait and Labrador Sea. Bull. U.S. Coast Guard, 19(2), 1-259.

Soule, F.M., 1940. Physical oceanography -- the Grand Banks region and the Labrador Sea in 1940. U.S. Coast Guard. International ice observation and ice patrol service, Bulletin. 30, 36-56.

Straneo F. and F. Saucier, 2008. The outflow from Hudson Strait and its contribution to the Labrador Current. Deep-Sea Research I, 55, 926-946.

Stroeve, J., and W. Meier, 2008. Sea Ice Trends and Climatologies from SMMR and SSM/I, Monthly means 1979-2007. Boulder, CO: National Snow and Ice Data Center. Digital media (http://nsidc.org/data/nsidc-0192.html).

Sutcliffe Jr., W. H., R. H. Loucks, K. F. Drinkwater, and A. R. Coote, 1983. Nutrient flux onto the Labrador Shelf from Hudson Strait and its biological consequences. Canadian Journal of Fisheries and Aquatic Sciences, 40, 1692-1701.

Sverdrup, H. U., 1942. Oceanography for Meteorologists. Prentice Hall, 246 pp.

Teller, J. T., D. W. Leverington, and J. D. Mann (2002), Freshwater outbursts to the oceans from glacial Lake Agassiz and their role in climate change during the last deglaciation, Quat. Sci. Rev., 21, 879- 887.

Therriault, J.-C., et al., 1998. Proposal for a northwest Atlantic zonal monitoring program, Can Tech. Rep. Hydrogr. Ocean Sci., 194, Ocean Sci. Div. of Fish. And Ocean Can., Dartmouth, N. S., Canada, 57 pp.

Townsend T. L., H. E. Hurlburt, P. J. Hogan, 2000. Modeled Sverdrup flow in the North Atlantic from 11 different wind stress climatologies. Dynamics of Atmospheres and Oceans, 32, 373-417.

Umoh, J. U., J. W. Loder, and B. Petrie, 1995. The role of air-sea heat fluxes in annual and interannual temperature variability on the eastern Newfoundland Shelf. Atmosphere-Ocean, 33(3), 531-568.

Voorheis, G. M., K. Aagaard, and L. K. Coachman, 1973. Circulation patterns near the Tail of the Grand Banks. J. Phys. Oceanog., 3, 397-405.

Worthington, L. V., 1976. On the North Atlantic Circulation, The Johns Hopkins Oceanographic Studies, No. 6, The Johns Hopkins University Press, Baltimore, MD, 110 pp. 
Worthington, L. V. and W. G. Metcalf, 1961. The relationship between potential temperature and salinity in deep Atlantic water. Rapports et Proces-Verbaux des Reunions Extrait du Journal du Conseil Internation Pour L'Exploration de la Mer, 149, 122-28. 


\section{Figure Captions:}

Figure 1: Schematic diagram depicting major features of the surface circulation in the western North Atlantic. The geographic names of relevant shelves, channels, and topographic features are also given. AC is Avalon Channel and FP is Flemish Pass. The International Ice Patrol standard section, A3, and the WOCE repeat section, AR19 are also shown.

Figure 2: Temporal and spatial distribution of the historical hydrographic station data used in the construction of climatological fields. The histogram shows the fraction of stations per year that were occupied during a summer-centered (Apr.-Sep.; red) and a winter-centered (Oct.-Mar.; blue) 6-month period. The data density maps show the total number and seasonal fraction of stations that contributed to a particular node in the final grid within the Shelf Water Layer $\left(\sigma_{0} \leq\right.$ 26.80).

Figure 3: Mean sections of salinity (color) calculated from 6 synoptic occupations of the WOCE repeat line AR19, averaging along (a) isopycnals and (b) constant pressure. $\sigma_{0}=26.80$ is shown by the white contour. (c) Temperature-salinity profiles extracted near $375 \mathrm{~km}$ (vertical black line in panel a \& b). The profiles from individual synoptic stations (black) are compared with those from the isopycnally averaged (blue) and isobarically averaged (orange) stations. The red curve is the standard T-S curve constructed by Armi \& Bray (1982) for WNACW. (d) As in (c) but comparing density-depth profiles.

Figure 4a: (top) Range of salinity anomaly along a given isopycnal. The $\sigma_{0}=26.80$ is denoted by the vertical line. (bottom) Temperature-salinity relation for all of the station data collected in 6 synoptic occupations of the AR19 WOCE repeat line, color-coded by salinity anomaly. Salinity anomaly is calculated as a function of density relative to a time-independent standard T-S curve 
constructed by Armi \& Bray (1982) from observations in the Sargasso Sea (black). The heavy light gray contour shows the $\sigma_{0}=26.80$ isopycnal used to define the Shelf Water Layer. Positive anomalies are shown in dark gray.

Figure 4b: Salinity anomaly within the Shelf Water Layer $\left(\sigma_{0} \leq 26.80\right)$ calculated from the 100 year mean salinity distribution in the climatology. The gray masking shows where the layer is outcropped. Anomalies greater than -0.5 are shown in white. The 100, 200, 500, 1000, 2000, 3000 , and 4000 meter isobaths are shown in black.

Figure 5: (a) Regional map showing the path along which the Hovmöller diagrams in Fig. 5b and Fig. $5 \mathrm{c}$ are calculated. The heavy black line follows the shelfbreak and the main branch of the LC corresponding to Figure $5 \mathrm{~b}$ and the thinner black line follows the inner LC branch corresponding to Figure $5 \mathrm{c}$. The schematic circulation for the main LC branch and the inner LC branch is shown in gray. White circles and squares are geographical markers to orient the reader, corresponding to the horizontal lines in Figures $5 \mathrm{~b}$ and $5 \mathrm{c}$. The location of the three cross-shelf sections shown in Figure 6 are also depicted. The 100, 200, 500, 1000, 2000, 3000, and 4000 meter isobaths are shown in black.

(b) Monthly mean salinity anomaly averaged over the Shelf Water Layer $\left(\sigma_{0} \leq 26.80\right)$ within a $100 \mathrm{~km}$ swath following the shelfbreak between the Labrador Shelf and the southwest Grand Banks. The gray masking shows where the layer is outcropped. The horizontal grid lines align with the geographical markers on (5a) as denoted by the circles and squares. Vertical gridlines are shown to aid visualization.

(c) Monthly mean salinity anomaly averaged over the Shelf Water Layer $\left(\sigma_{0} \leq 26.80\right)$ within a $100 \mathrm{~km}$ swath following the inner branch of the LC between the Labrador Coast and Flemish 
Pass. The gray masking shows where the layer is outcropped. The horizontal grid lines align with the geographical markers on (a) as denoted by the circles and squares. Vertical gridlines are shown to aid visualization.

Figure 6: Monthly mean salinity anomaly averaged over the Shelf Water Layer $\left(\sigma_{0} \leq 26.80\right)$ across the shelf and slope at (a) Flemish Cap, (b) across the eastern flank of the Grand Banks, and (c) at the Tail of the Grand Banks. The origin of each section is aligned with the shelfbreak so that negative positions are on the shelf. Vertical white gridlines show the $100 \mathrm{~km}$ swath centered on the shelfbreak for comparison with Figure $5 b$. The gray masking shows where the layer is outcropped.

Figure 7: Offshore limit of the freshwater boundary defined where the salinity anomaly is less than -3.0 for March (dark blue) and September (light blue) and in the 100-year mean (black). The gray shaded region shows where the depth of the $\sigma_{0}=27.25$ isopycnal (within the main pycnocline) is shallower than $200 \mathrm{~m}$. The offshore edge of this region is an indicator of the inshore edge of the NAC (see text). The 100, 200, 500, 1000, 2000, 3000, and 4000 meter isobaths are shown in black.

Figure 8: The 100-year mean depth of the $\sigma_{0}=27.25$ isopycnal, located within the main pycnocline ( $\mathrm{ci}=25 \mathrm{~m}$ for $\mathrm{z}=0-200 \mathrm{~m}$; $\mathrm{ci}=50 \mathrm{~m}$ for $\mathrm{z}=200-800 \mathrm{~m}$ ). The white masking represents the region where this isopycnal is grounded. The crest of the pycnocline ridge is traced by the heavy black line and dots are placed every $50 \mathrm{~km}$ along the transect for comparison with Figure 9b. The location of a cross slope section plotted in Figure 9a is traced by the white line and corresponds with IIP repeat section, A3. The statistics shown in Figure 13 were compiled from 
station data collected with the gray box surrounding A3. The approximate location of the core of the NAC is denoted by the black circle on A3.

Figure 8b: Dynamic height calculated relative to $1000 \mathrm{~m}$ from the 100 -year climatological mean hydrography along IIP repeat section A3 versus the depth of the $\sigma_{0}=27.25$ isopyncal.

Figure 9: Mean sections of temperature and salinity (color) with potential density (contours) (a) across (IIP repeat, A3) and (b) along the pycnocline ridge in Figure 8a. The heavy contours show $\sigma_{0}=26.80$ (lower bound on the Shelf Water Layer) and $\sigma_{0}=27.25$ (within the main pycnocline). The sections intersect one another at the vertical gray line, while the vertical dashed line in (a) shows the approximate location of the core of the NAC relative to A3. Shown top is the annual mean salinity anomaly averaged over the Shelf Water Layer across each section (black) and the cumulative baroclinic transport calculated from the thermal wind field derived from the section hydrography and referenced to zero velocity at $1000 \mathrm{~m}$ (red).

Figure 10: (a) Annual mean salinity anomaly averaged over the Shelf Water Layer $\left(\sigma_{0} \leq 26.80\right)$ within the LC immediately south of Flemish Pass (note the zoomed distance axis). (b) Monthly mean salinity anomaly averaged over the Shelf Water Layer within the LC immediately south of Flemish Pass. The location of the shelfbreak is denoted by the vertical line. The origin is aligned with the shelfbreak.

Figure 11: Mean vertical sections of salinity anomaly (color) and potential density (contours, $\mathrm{ci}=0.2$ solid for $\sigma_{0} \leq 27.20$ ) across the shelf and slope east of the Grand Banks for selected months in the climatology. $\sigma_{0}=26.80$ and $\sigma_{0}=27.25$ are depicted by the heavy contours showing the Shelf Water Layer and the isopycnal surface mapped in Figure 8a, respectively. 
$\sigma_{0}=27.50$ is shown by the dotted line. Salinity anomalies greater than -0.5 are masked white. The gray masking shows areas where grid nodes are empty.

Figure 12: (a) Monthly mean salinity anomaly averaged over the Shelf Water Layer $\left(\sigma_{0} \leq 26.80\right)$ for March-August. Contours showing the annual mean depth of $\sigma_{0}=27.25$ isopycnal are overlain to show the retroflection ridge geometry (heavy contours, ci=100 m; light contours, $\mathrm{ci}=50 \mathrm{~m}$ for $\mathrm{z} \leq 200 \mathrm{~m}$ ). The gray areas show where the Shelf Water Layer is outcropped.

Figure 12: (b) As in Figure 12a, but for September-February.

Figure 13: The percentage of all historical water samples (post-1950) collected within the Shelf Water Layer $\left(\sigma_{0} \leq 26.80\right)$ that contain one of three water types plotted as a function of distance along IIP repeat section, A3 (gray shaded curve). The three water classes are defined by their salinity anomalies, $S^{\prime}$, relative to WNACW (see text), where (a) fresh, (b) intermediate and (c) salty classes are defined by $S^{\prime} \leq-3,-3<S^{\prime} \leq-2, S^{\prime}>-2$, respectively. The origin of the x-axis is aligned with the crest of the pycnocline ridge, corresponding to the retroflection axis between the southward and northward flow regimes in A3 (see Figure 9a). The approximate location of the core of the NAC is denoted by the vertical dashed line. The seasonal curves shown in color represent the percentage of water samples containing a particular water class in spring (MayJuly), summer (Aug.-Oct.), fall (Nov.-Jan.), and winter (Feb.-Apr.).

Figure 14: The difference between the cumulative total NAC transport at a particular cross-slope position within the northward flow regime under the requirement that just mass is conserved and requiring that both mass (eq. 1) and salt (eq. 2) are conserved. The vertical gray line shows the position where mass conservation is satisfied by equation 1 . The vertical black line shows the position where both mass and salt conservation are satisfied (where the difference crosses zero). 
The origin of the $\mathrm{x}$-axis is aligned with the crest of the pycnocline ridge, corresponding to the retroflection axis between the southward and northward flow regimes in A3 (see Figure 9a).

Figure 15: (a) Annual mean layer-averaged salinity $\left(\sigma_{0} \leq 27.25\right)$ as a function of distance across the northward flow regime in section A3 (black) compared with the standard salinity of WNACW advected by the North Atlantic Current within this layer (gray). The origin of the $\mathrm{x}-$ axis is aligned with the crest of the pycnocline ridge, corresponding to the retroflection axis between the southward and northward flow regimes in A3 (see Figure 9a). (b) The salinity ratio (bracketed term in eq. 3) measuring the fraction of water at a given location that originates in the LC (black line). This is compared with the fraction of total historical water samples that contain either fresh or intermediate water (Figure 13a,b), together representing the percent occurrence of LC water across the northward flow regime (gray). (c) The cumulative northward transport of the retroflected LC (heavy black) and NAC (gray) as estimated from equations (3) and (1), respectively. The total transport is also shown by the thin black line. The approximate location of the core of the NAC is denoted by the vertical dashed line in all three panels.

Figure 16: Salinity anomaly averaged over the Shelf Water Layer $\left(\sigma_{0} \leq 26.80\right)$ from 6 synoptic hydrographic sections along WOCE repeat line AR19, crossing the eastern flank of the Grand Banks. The cumulative baroclinic transport calculated from the thermal wind field derived from the section hydrography is shown in red (referenced to the bottom). 


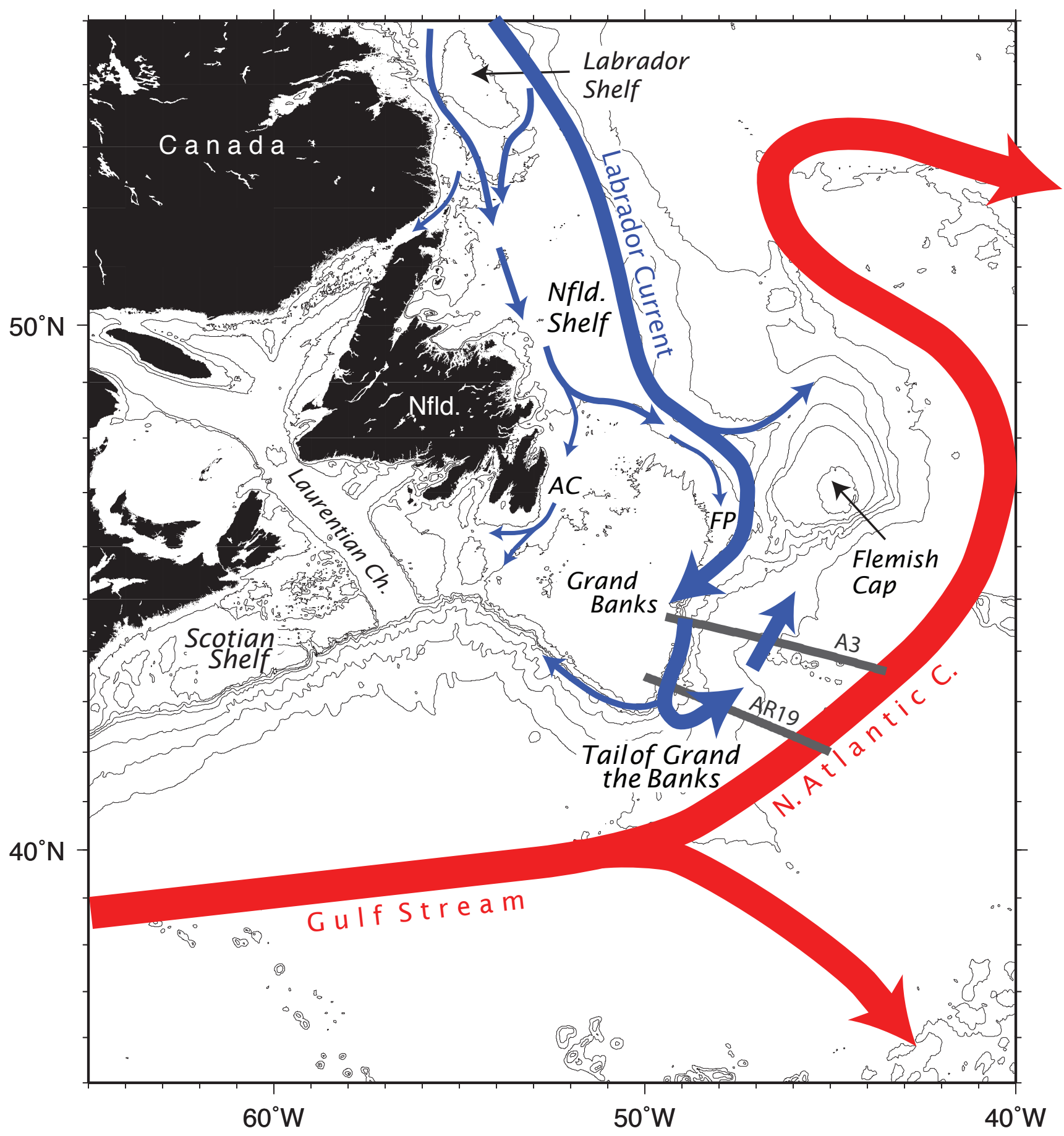

Figure 1 

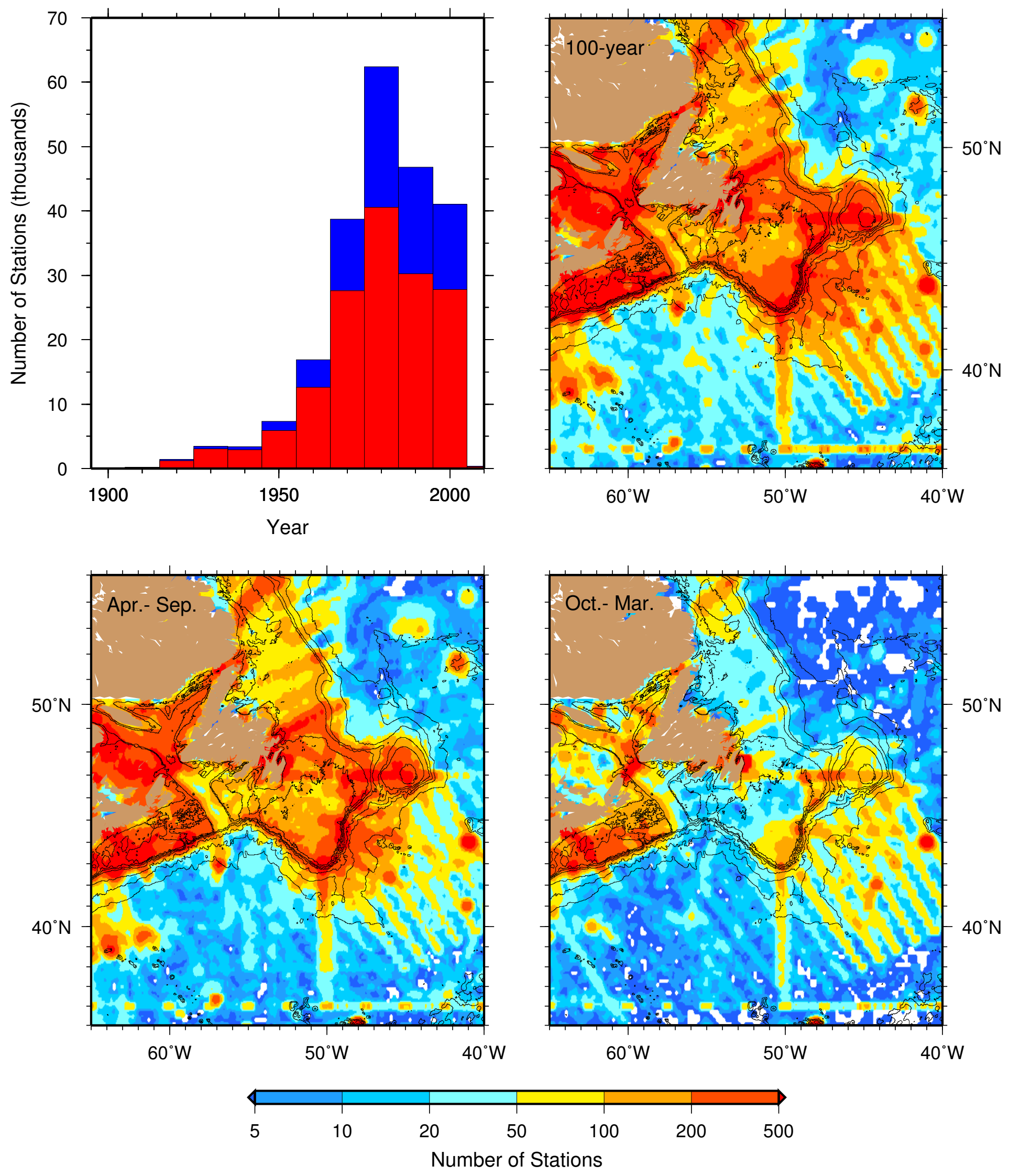

Figure 2 

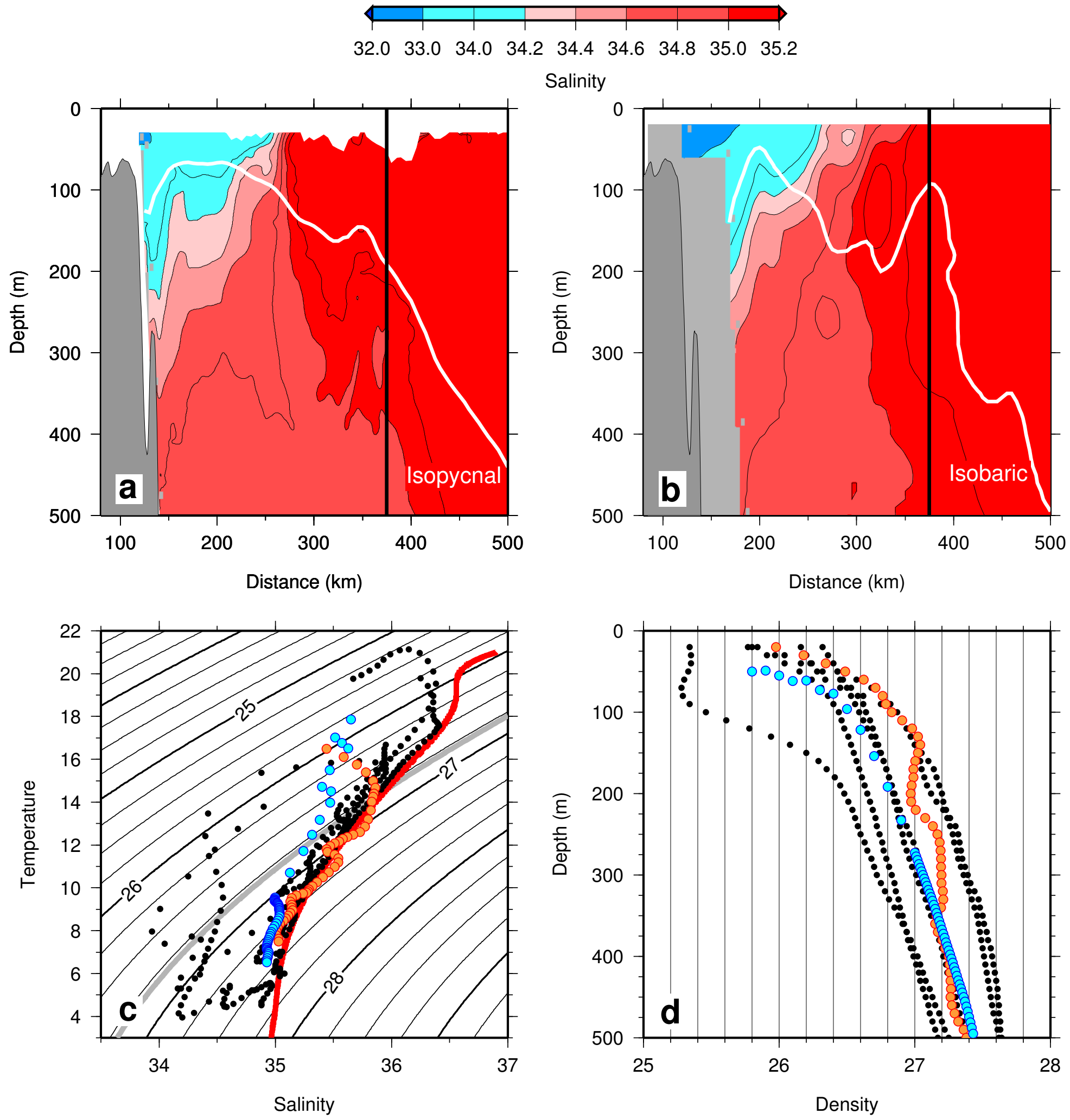

Figure 3 

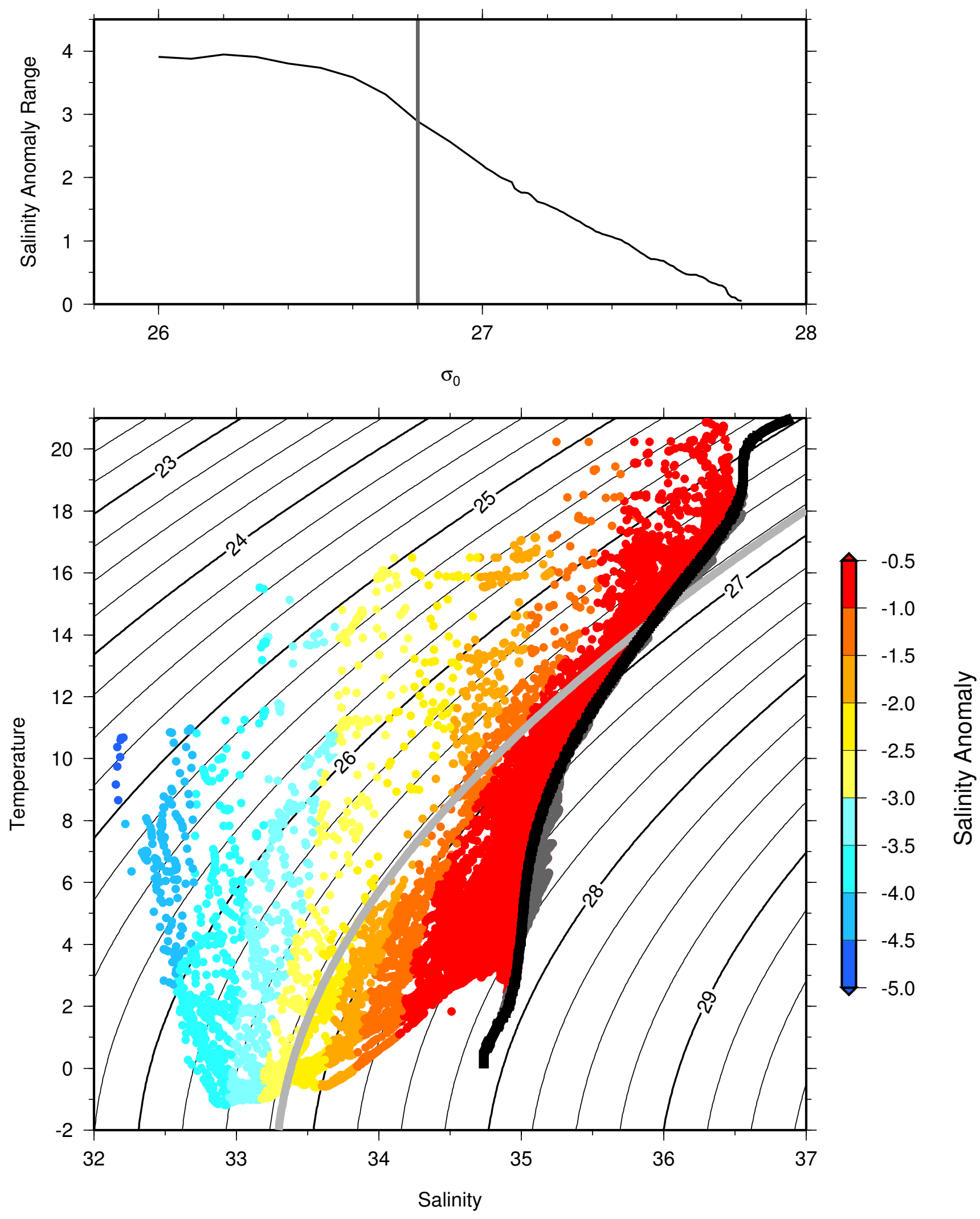

Figure $4 a$ 


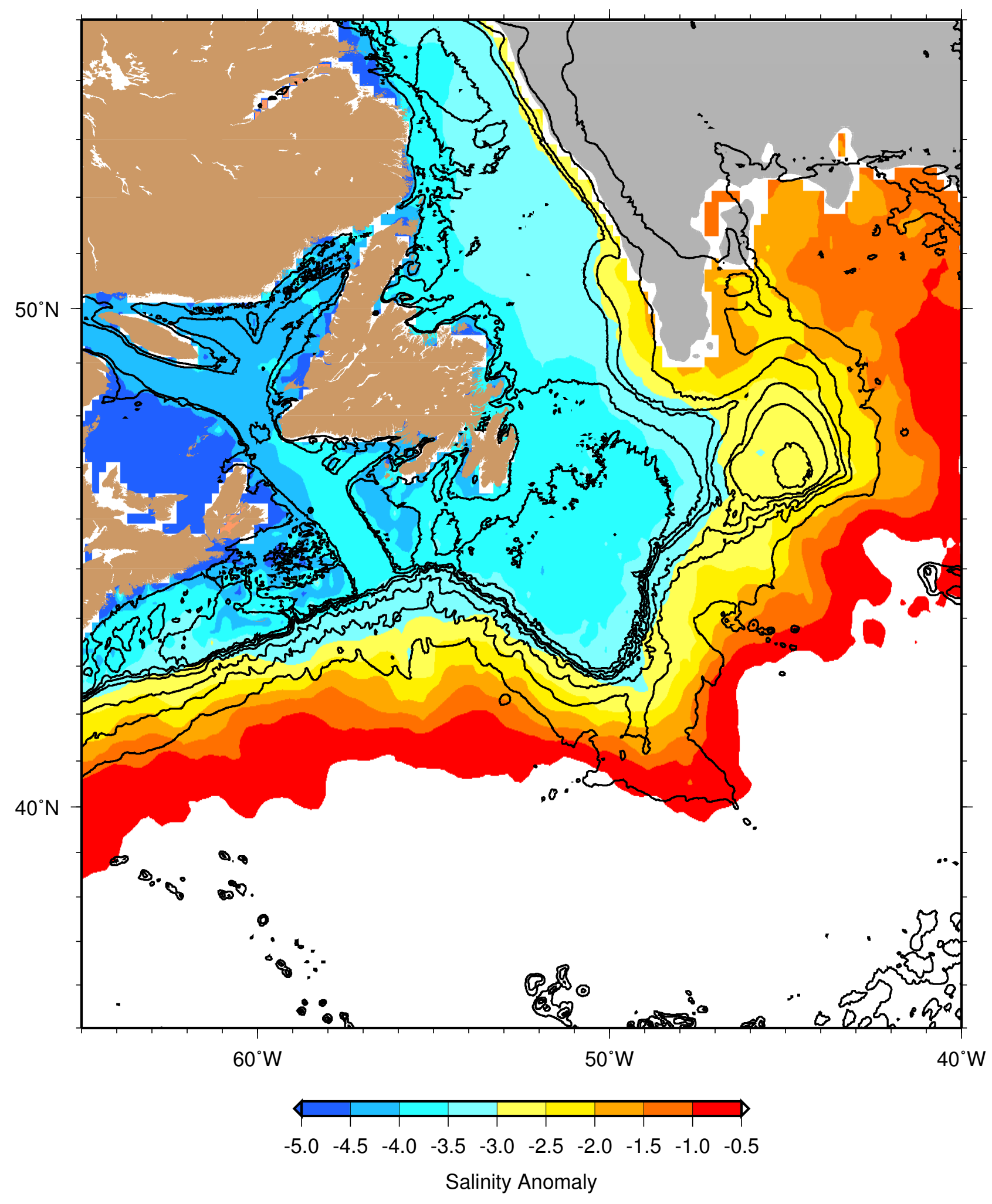

Figure $4 b$ 


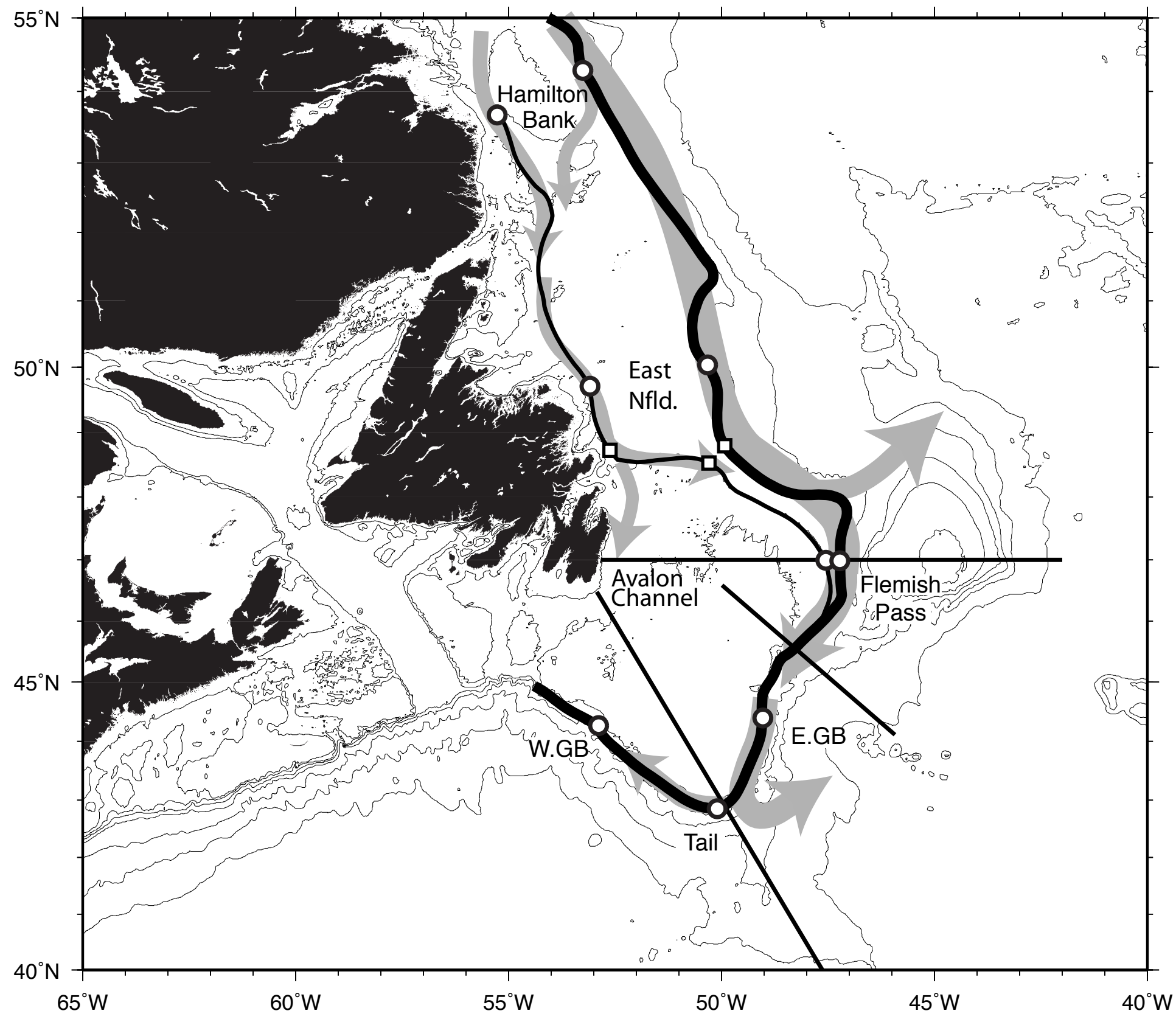

Figure 5a 
Along Shelfbreak

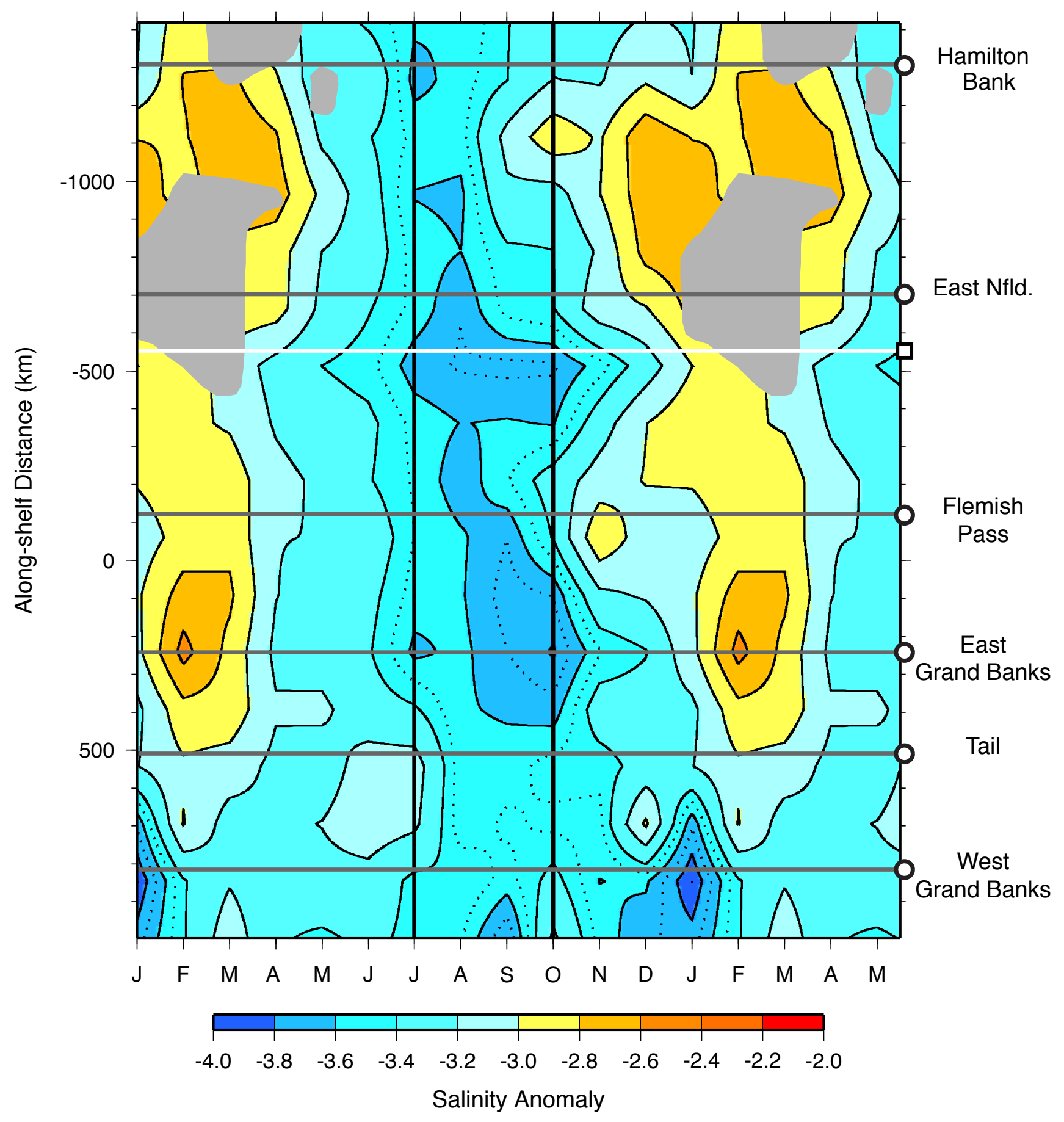

Figure 5b 


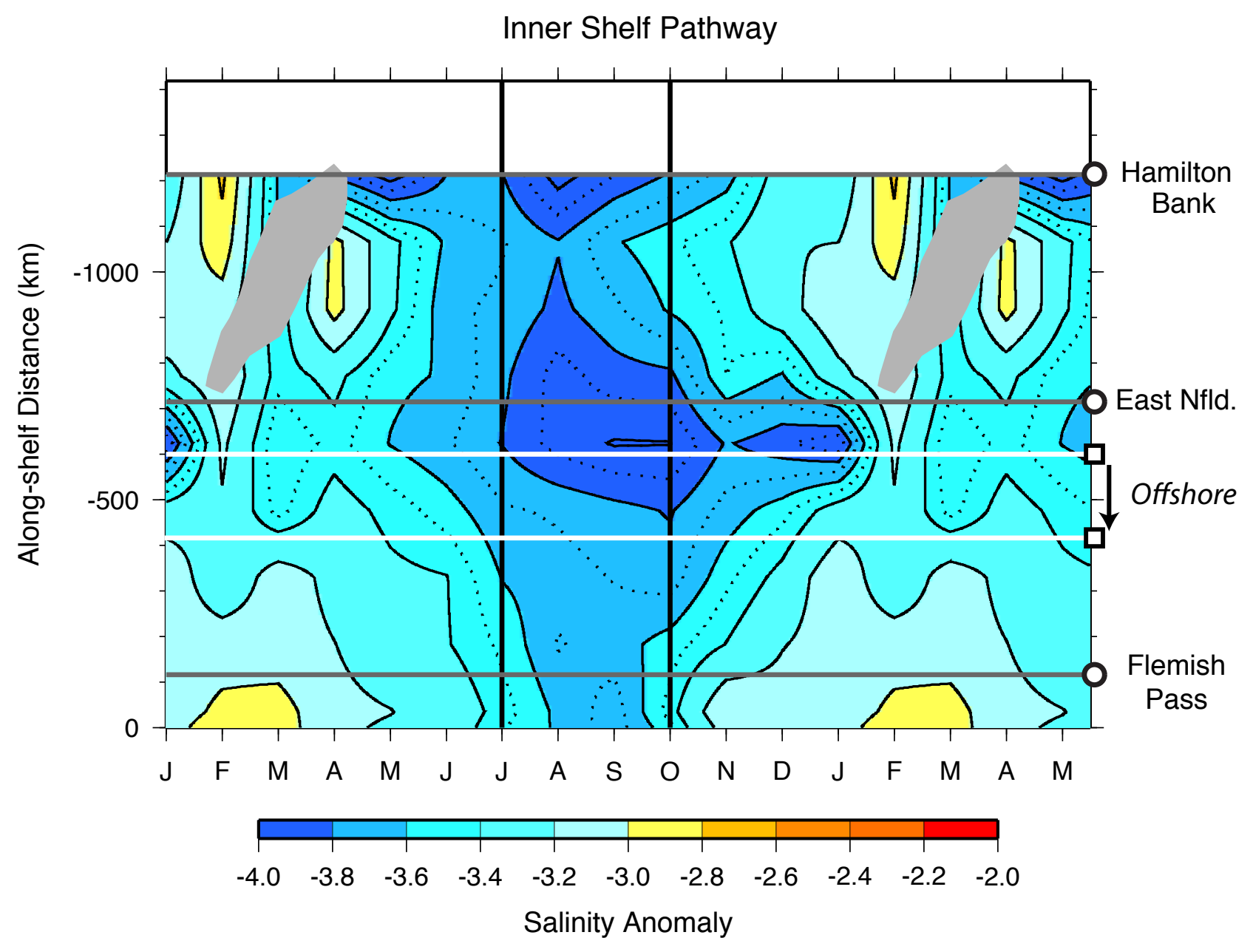

Figure 5c 


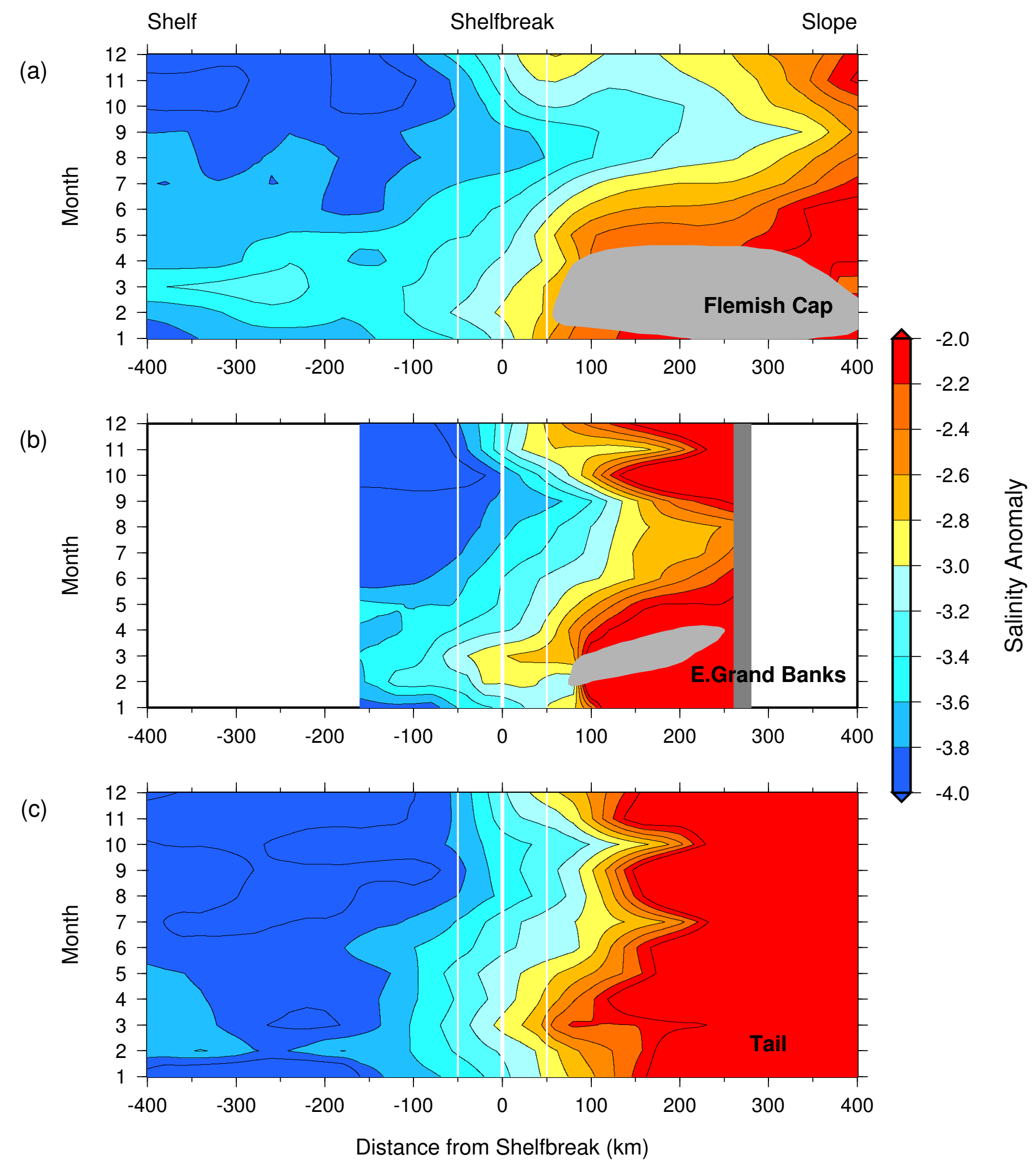

Figure 6 


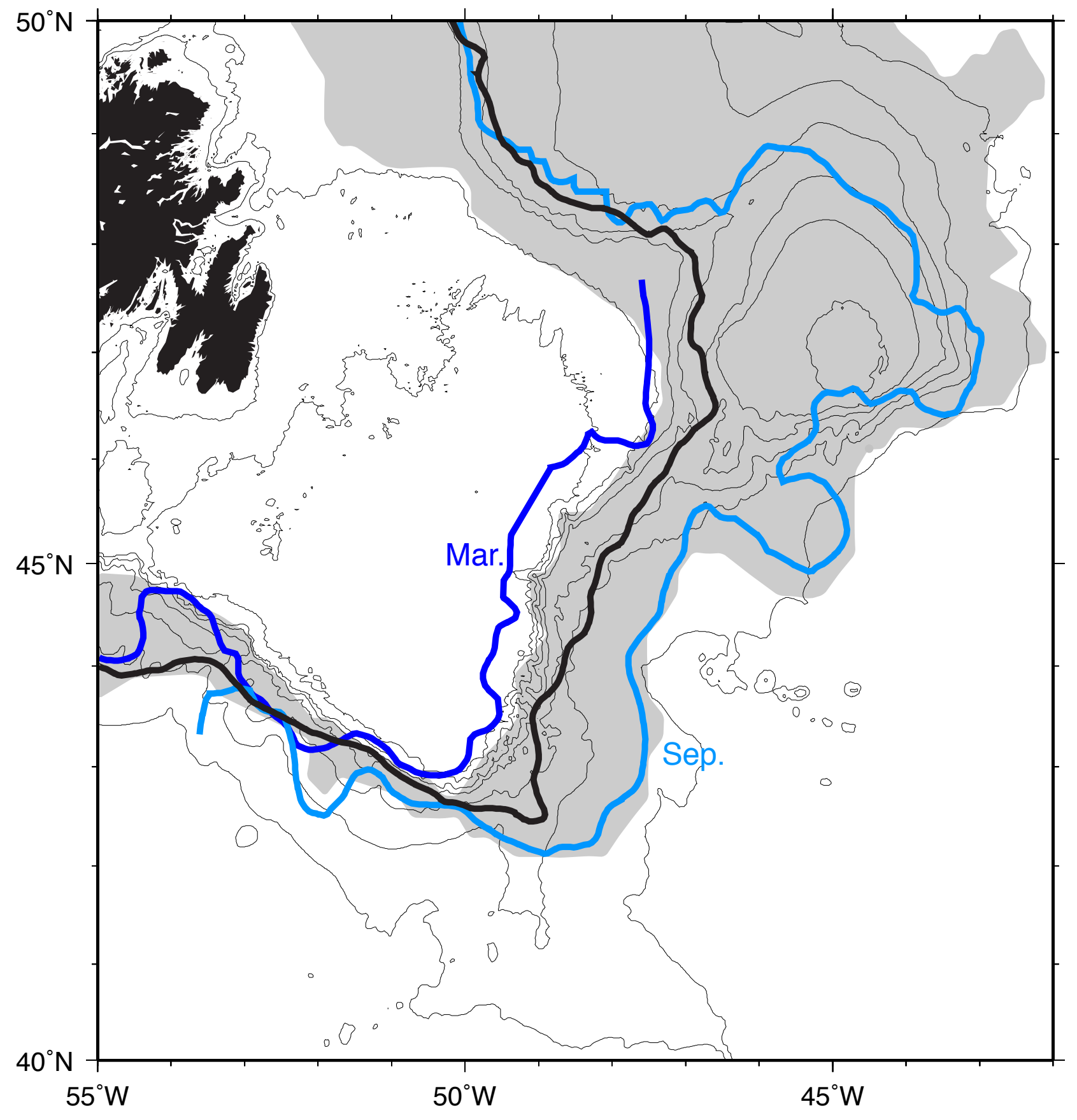

Figure 7 


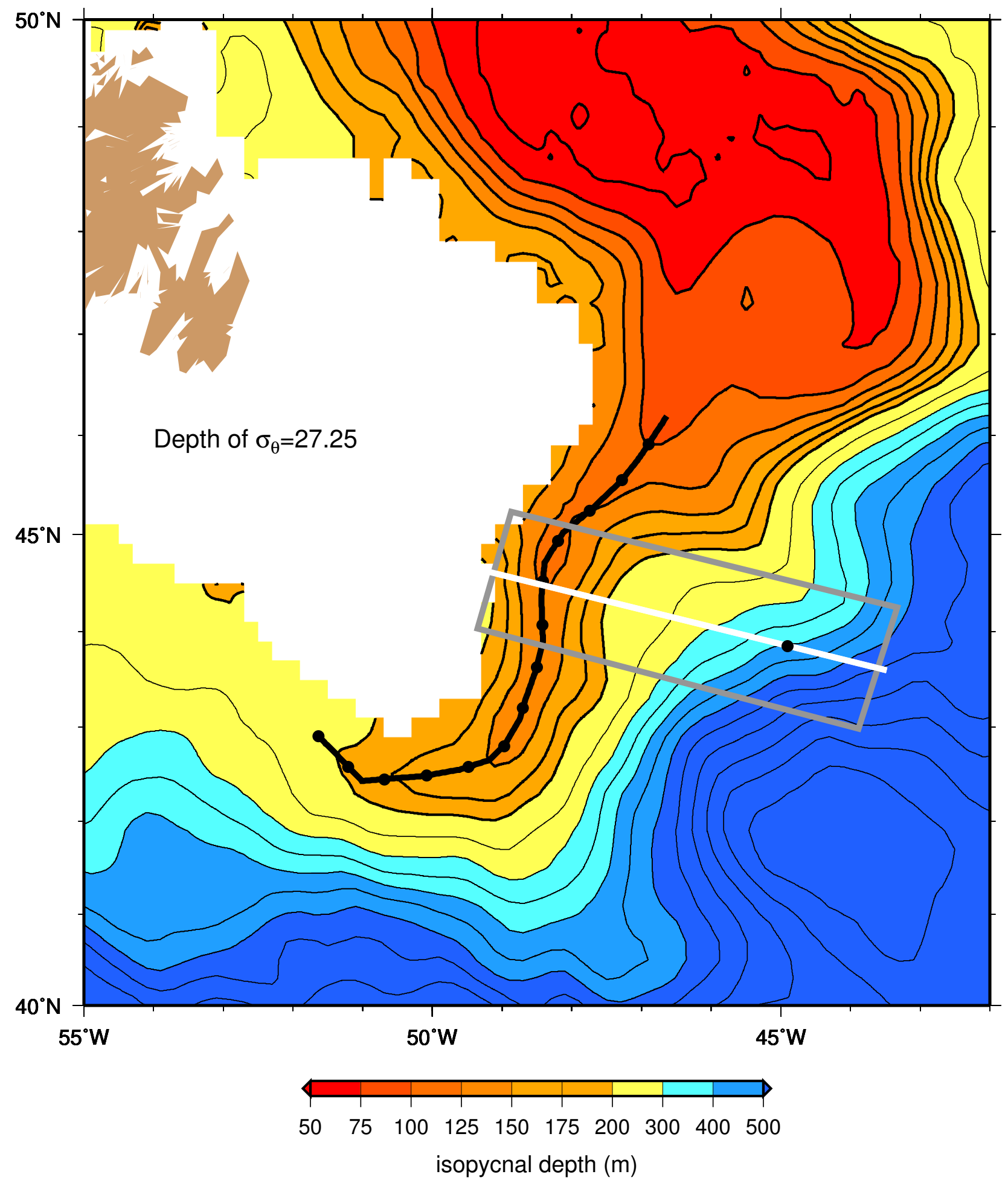

Figure $8 a$ 


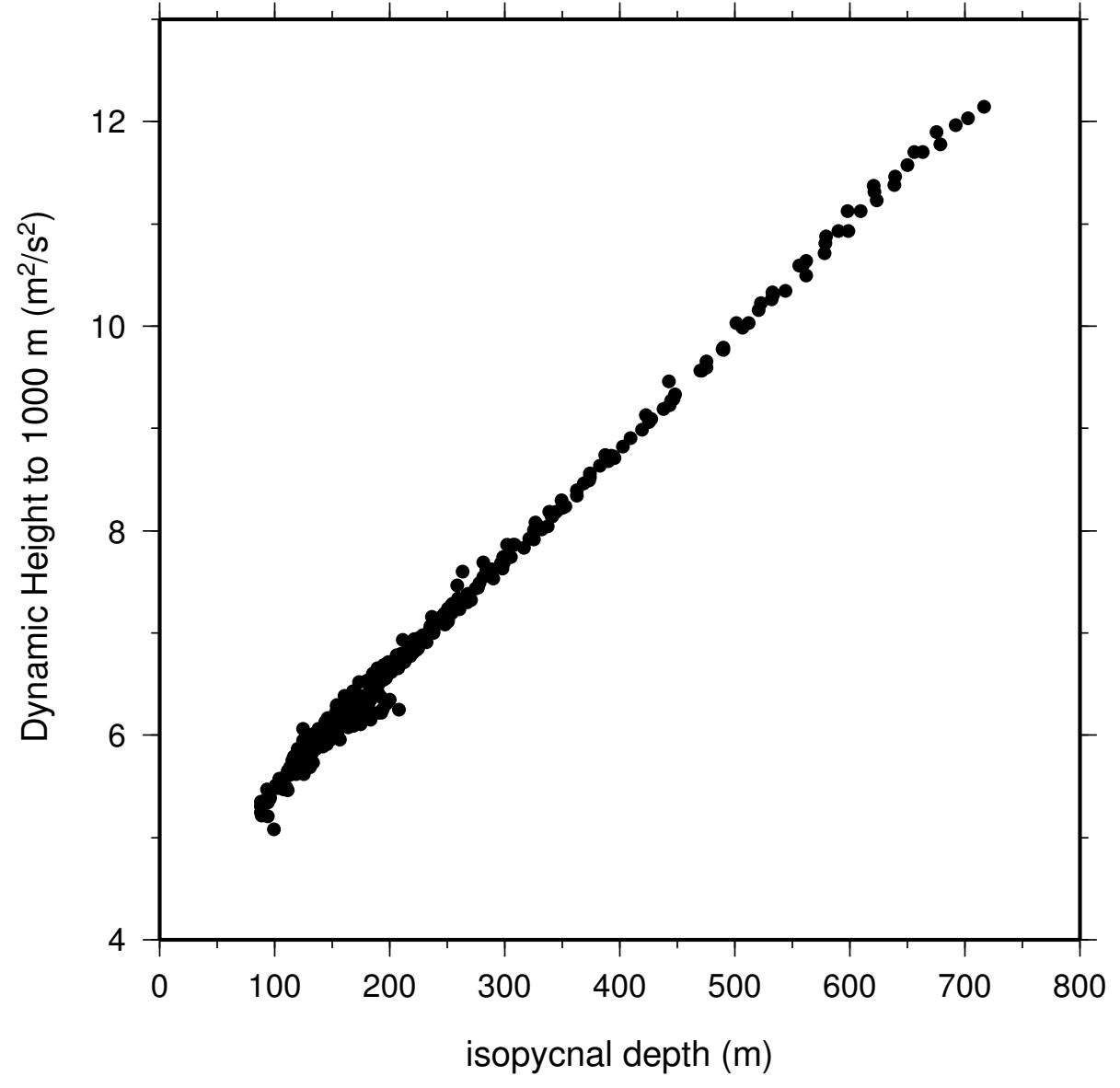

Figure $8 b$ 
(a) Cross-Ridge Section, A3

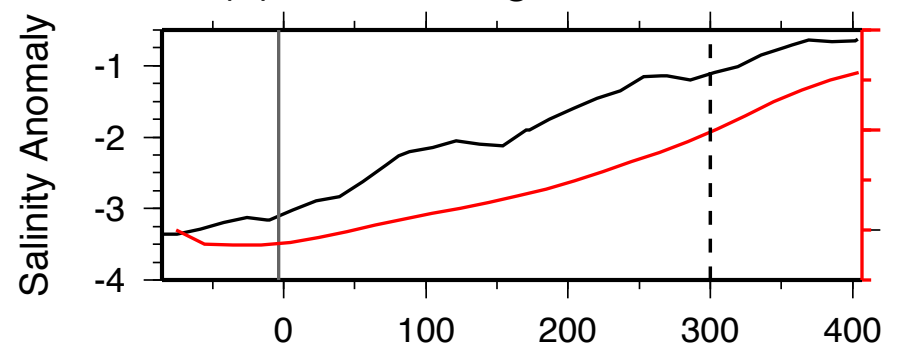

Shelf
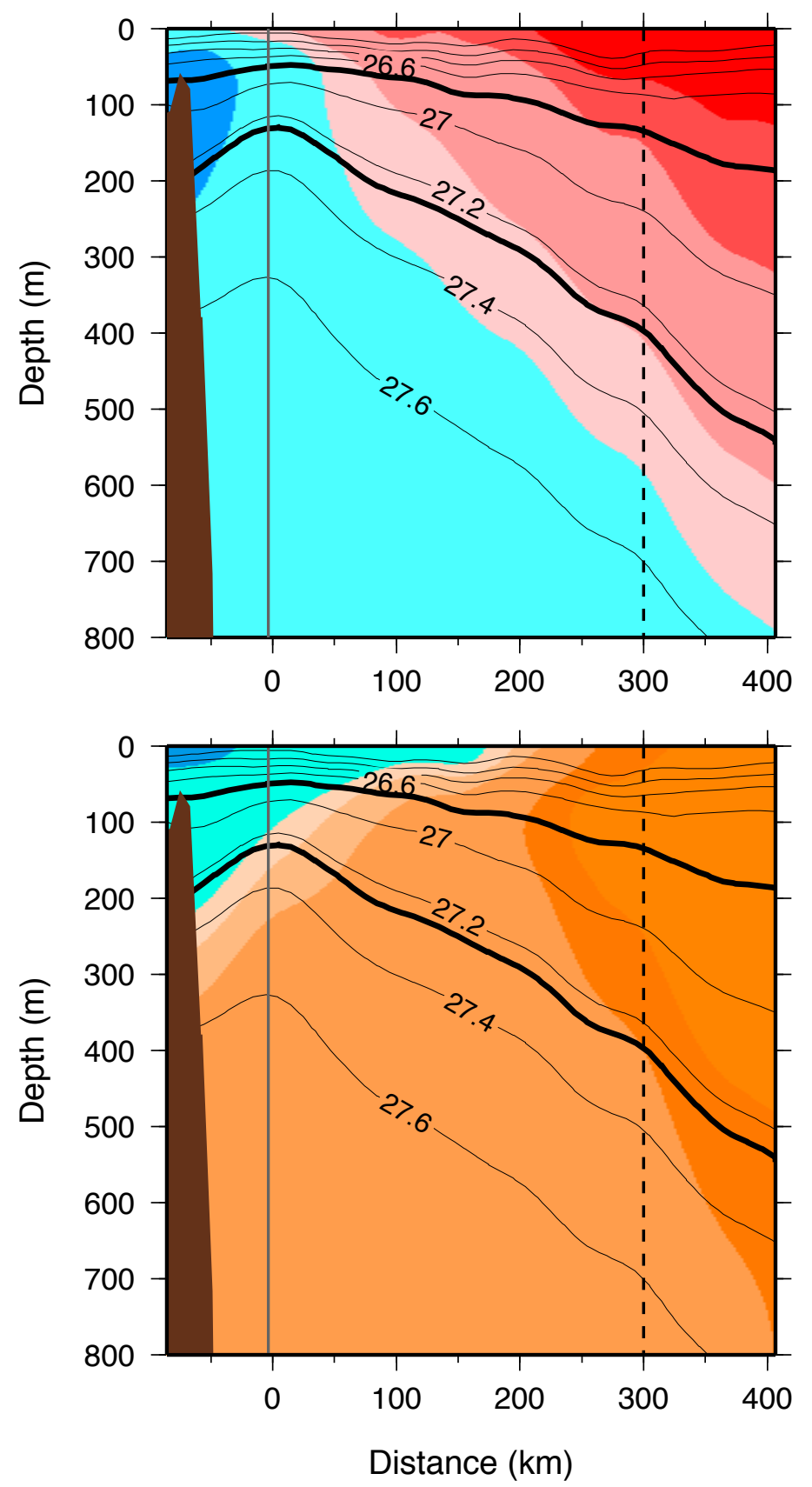

(b) Along-ridge Section

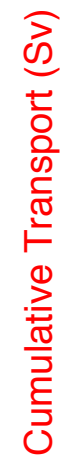

North
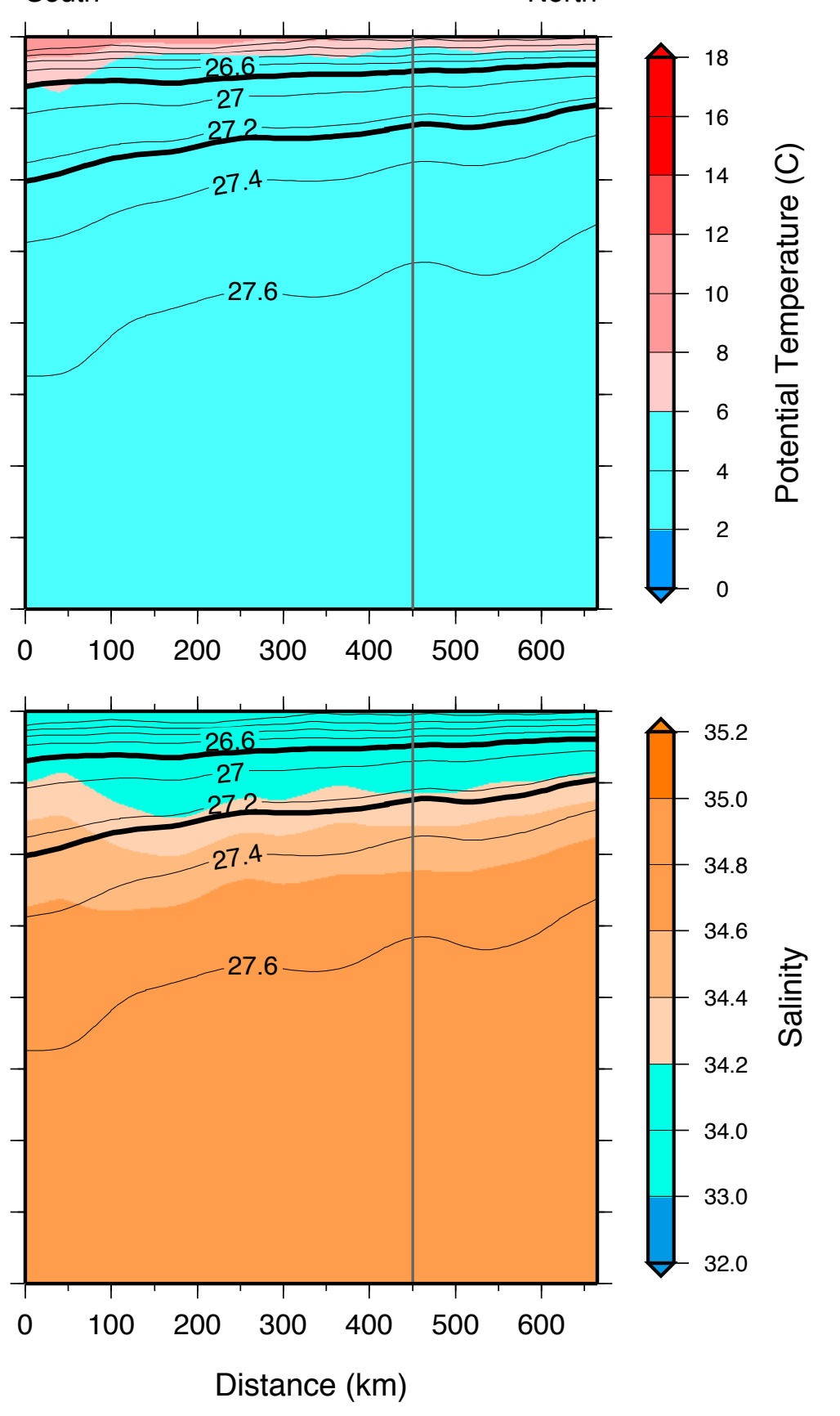

Figure 9 

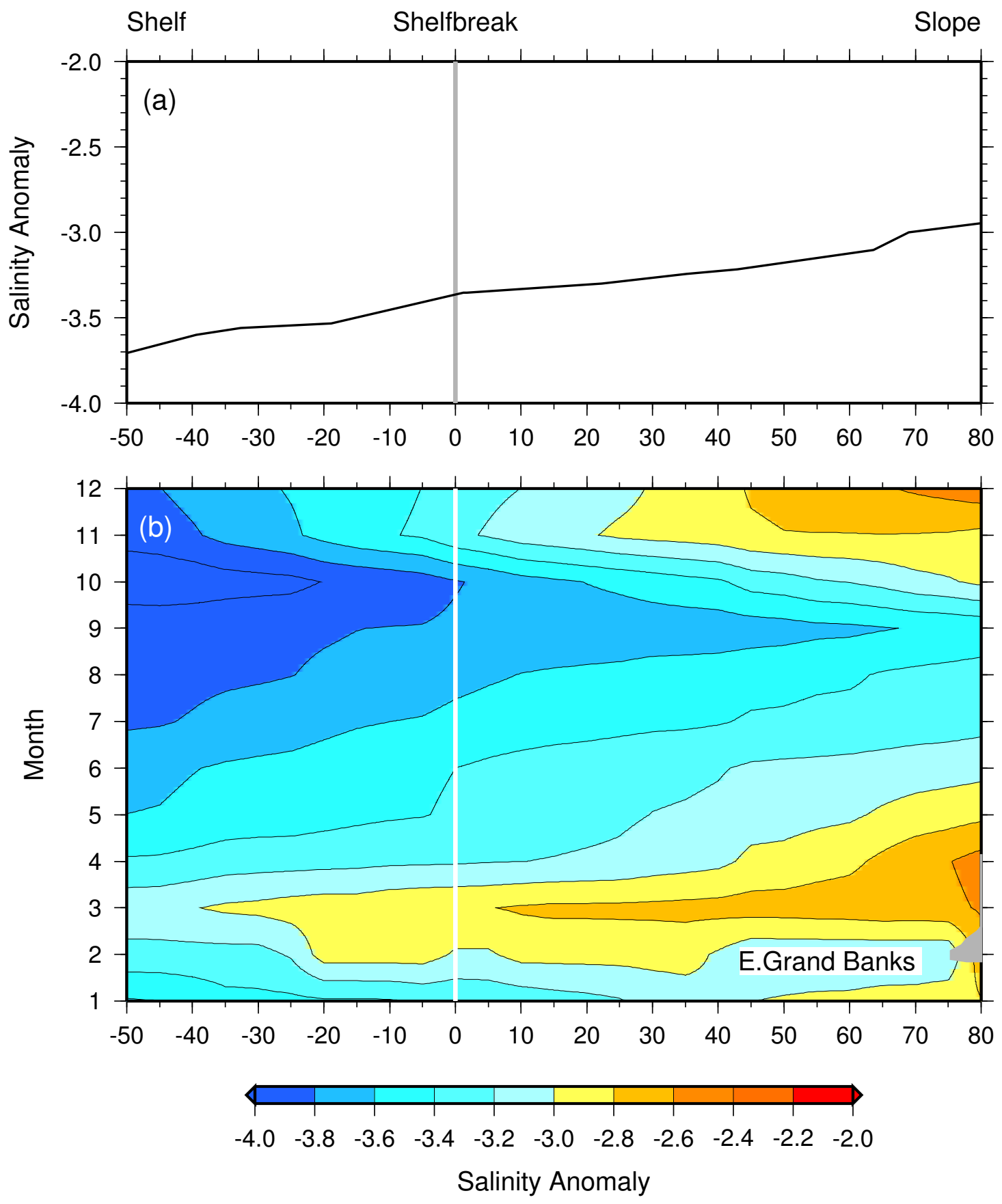

Figure 10 

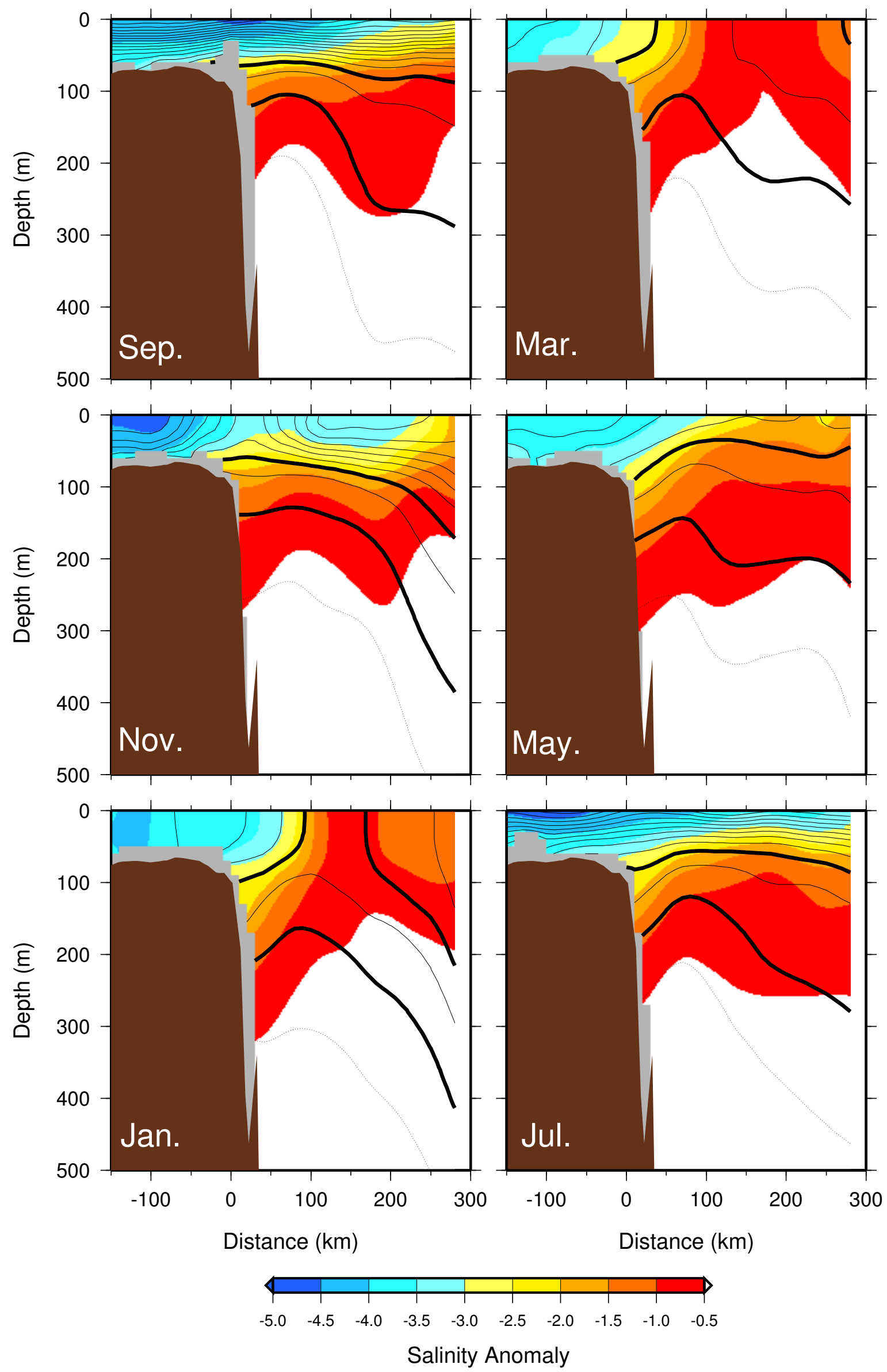

Figure 11 


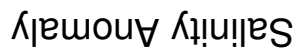
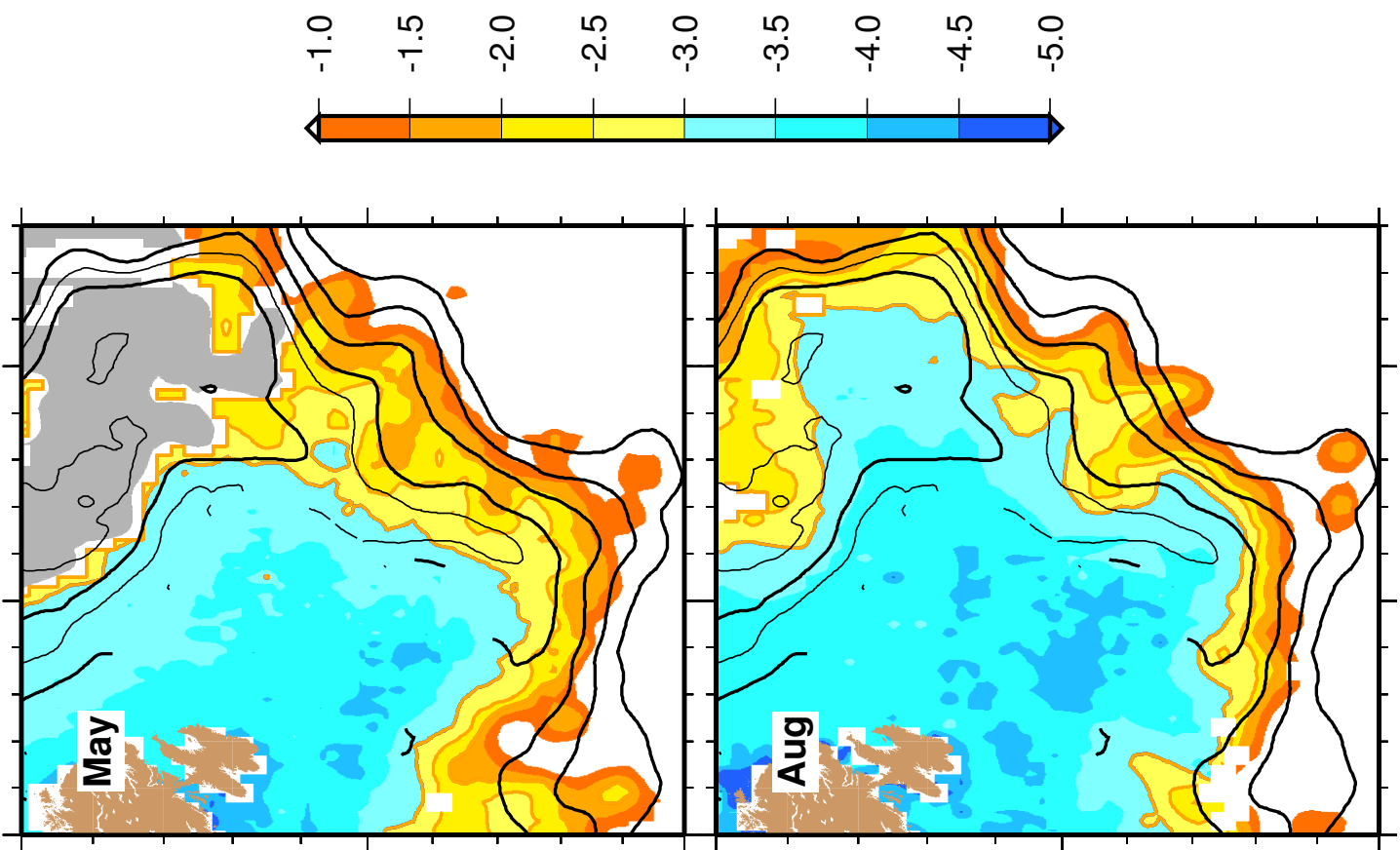

ㅁ
$\frac{0}{5}$
$\frac{0}{2}$
$i \frac{0}{4}$
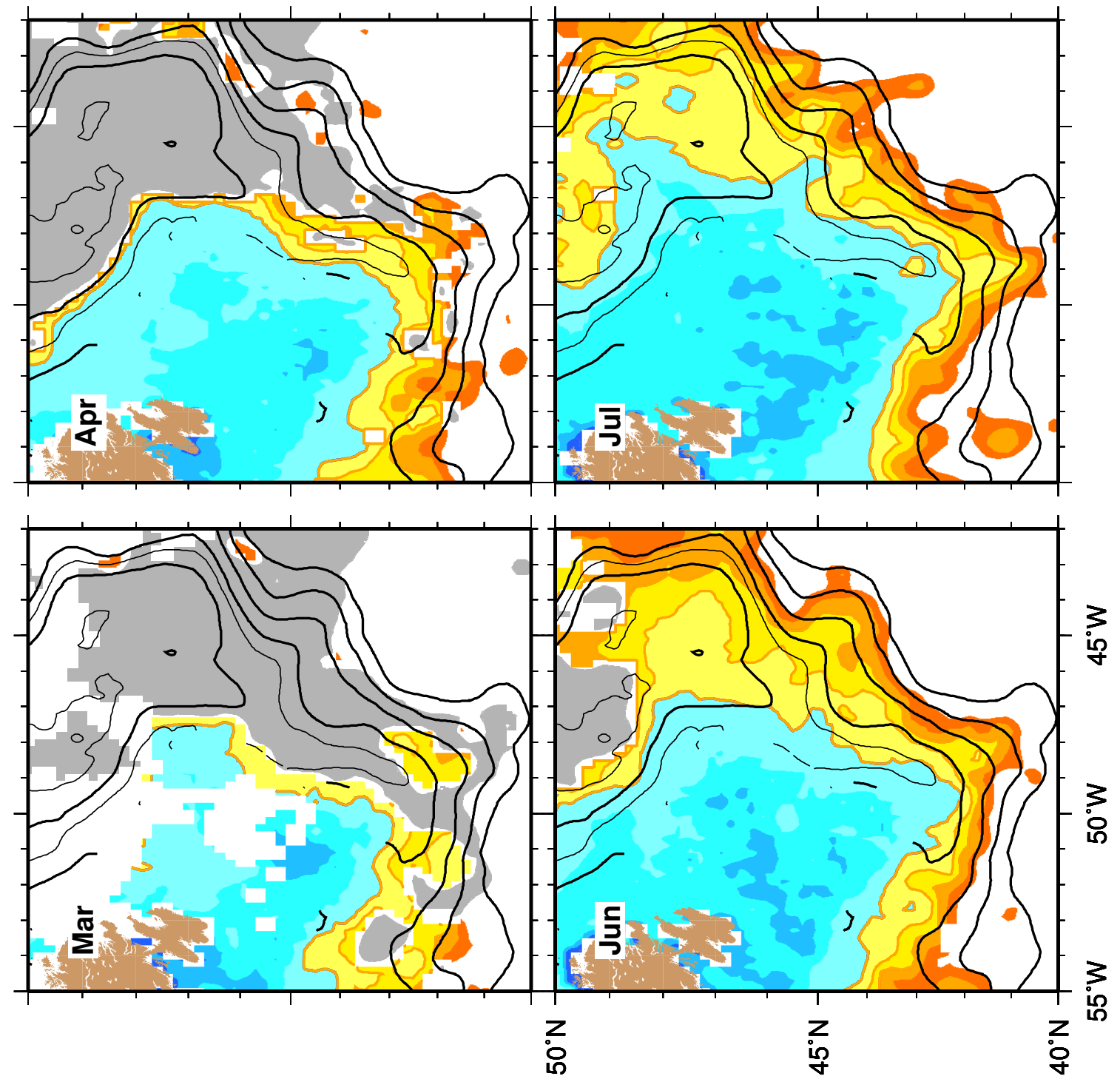


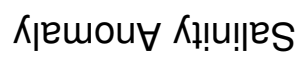
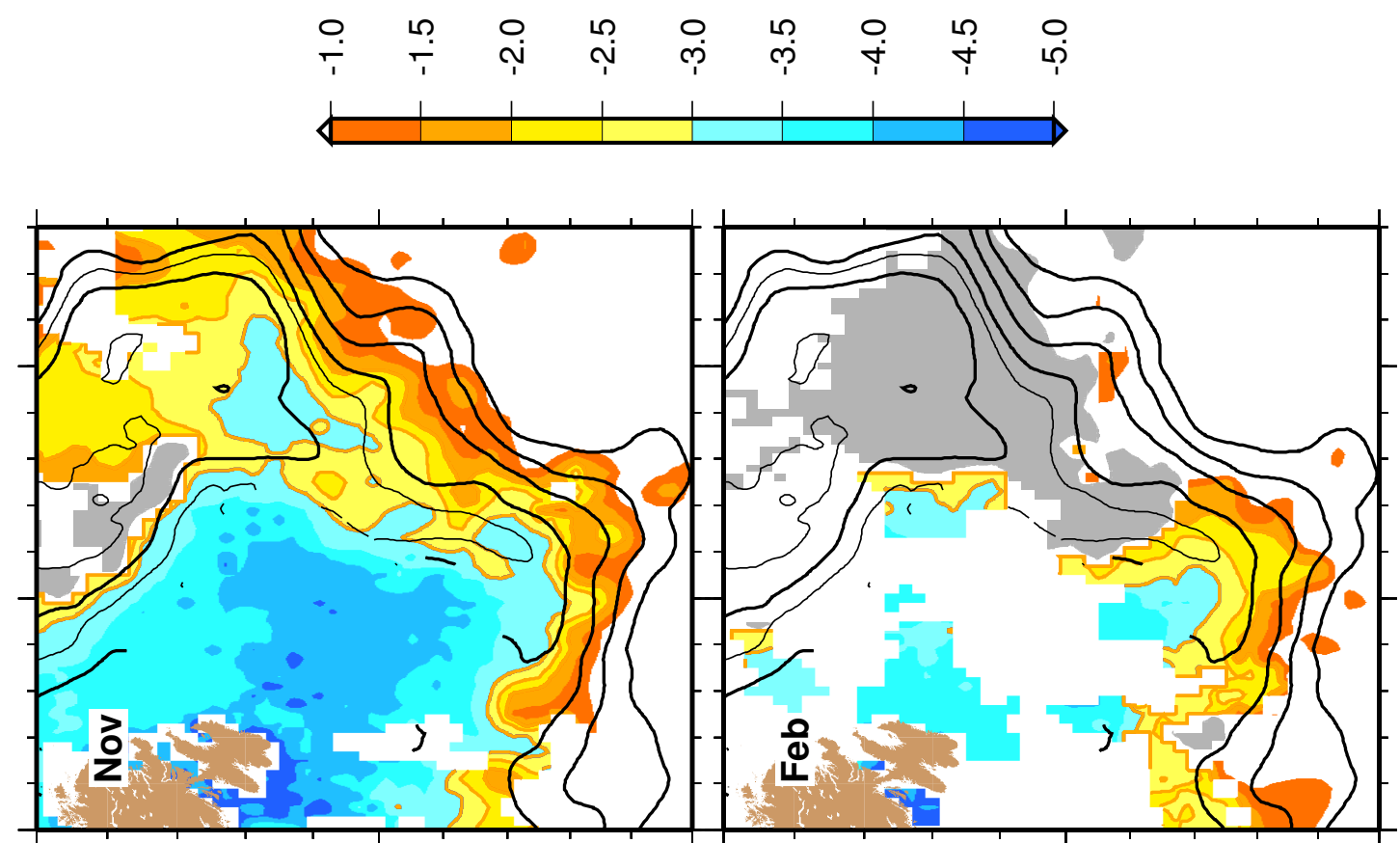

$\frac{0}{N}$
$\frac{0}{5}$
$\frac{0}{2}$
$i \frac{1}{2}$
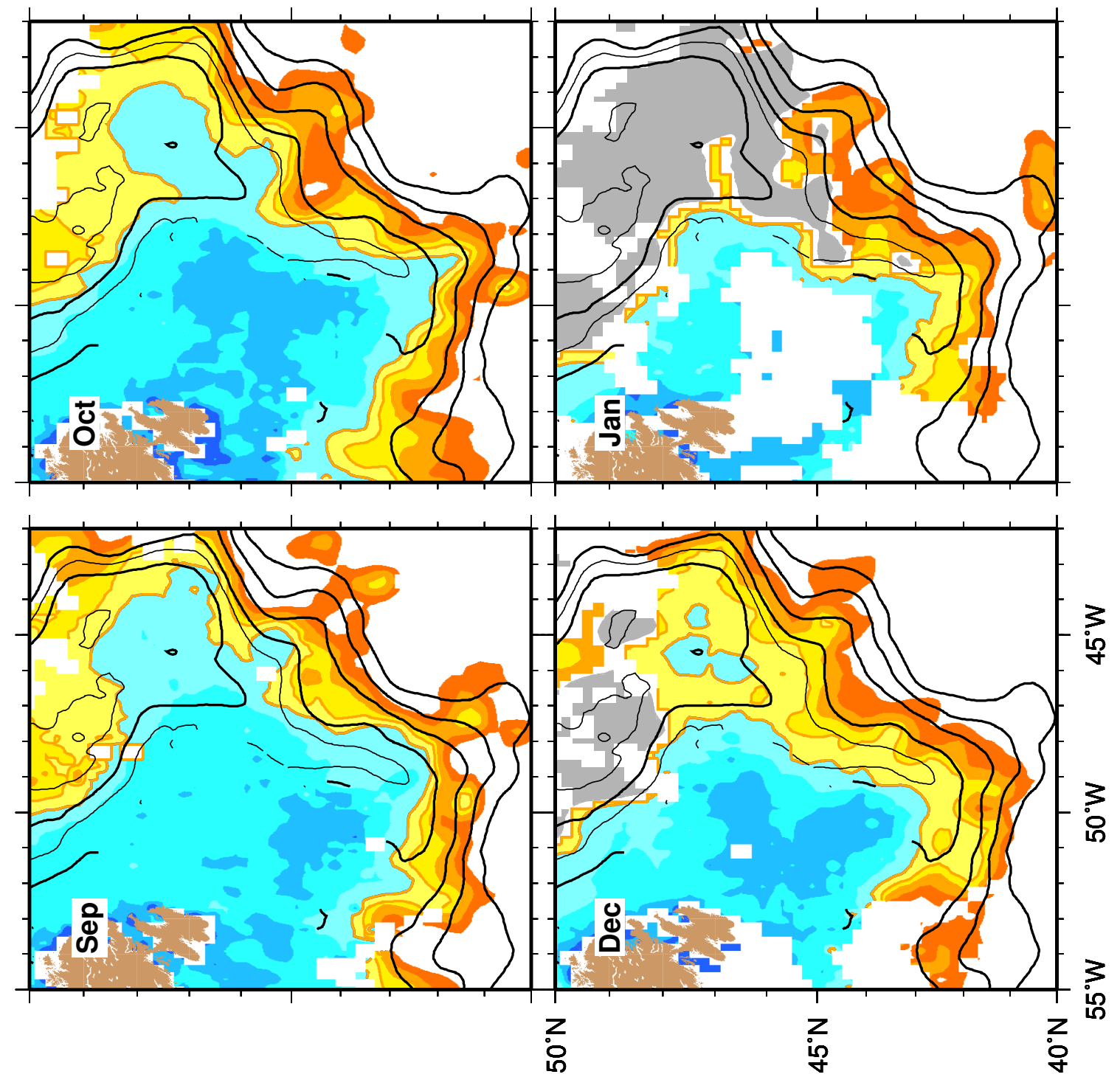

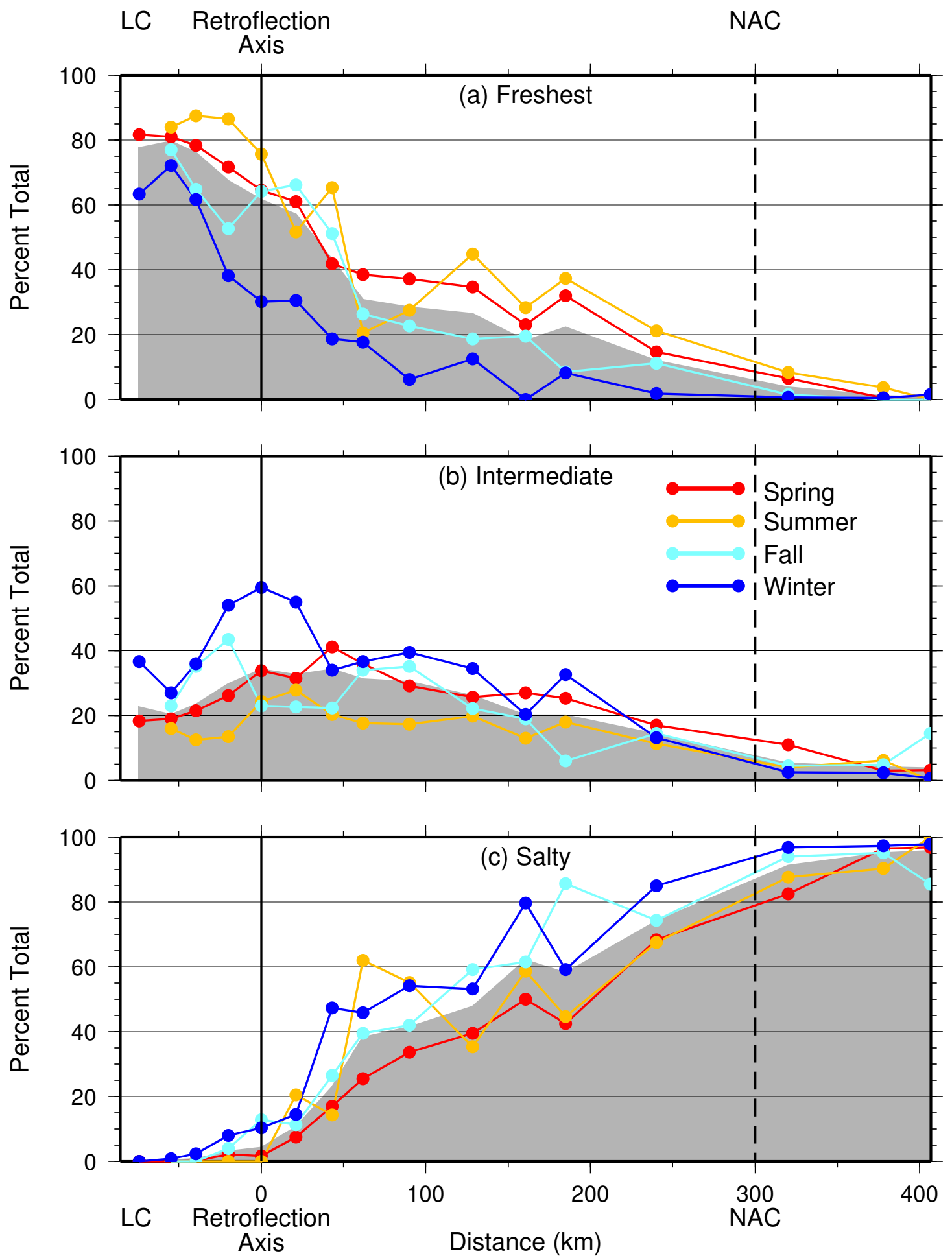

Figure 13 


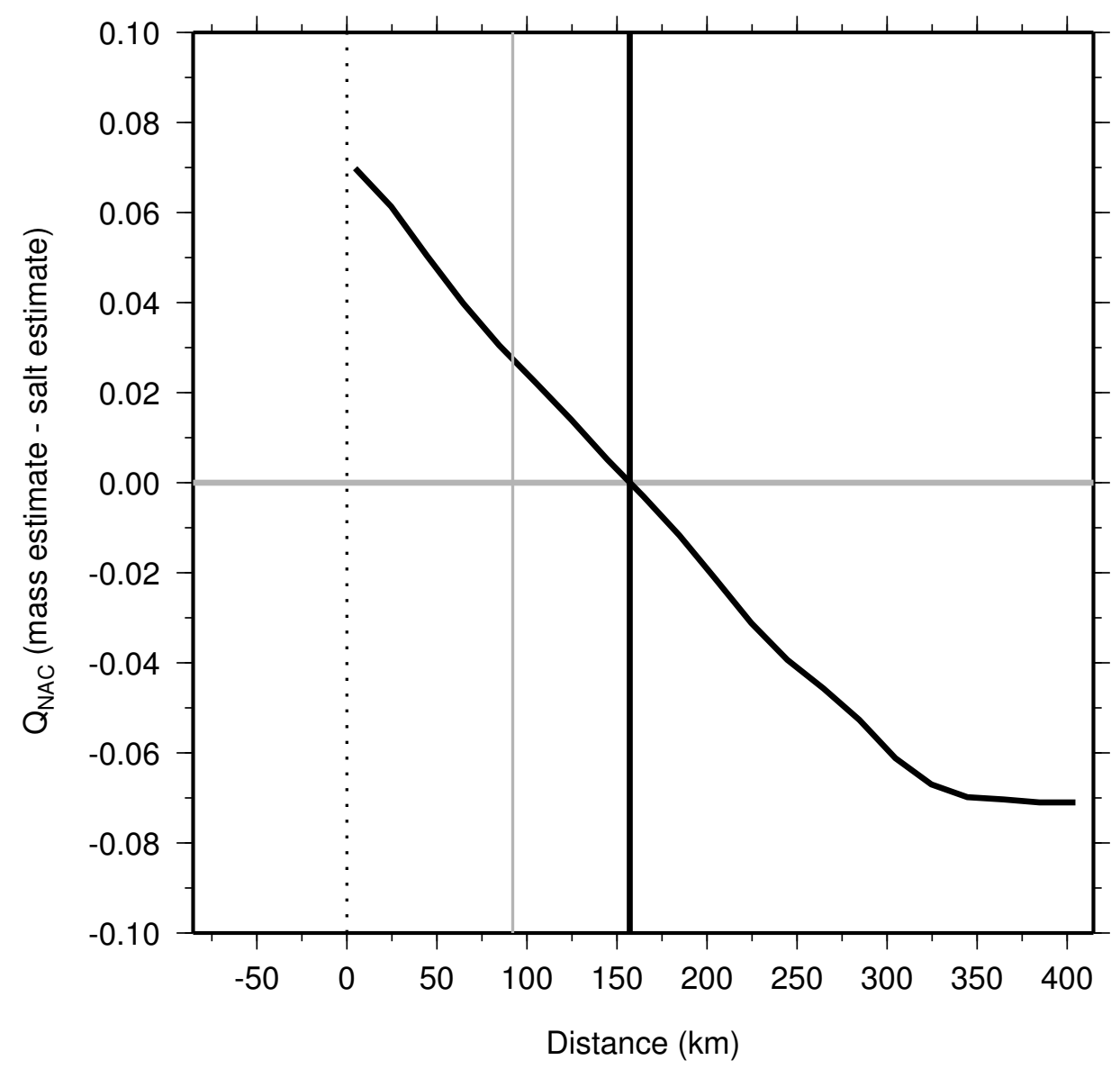

Figure 14 

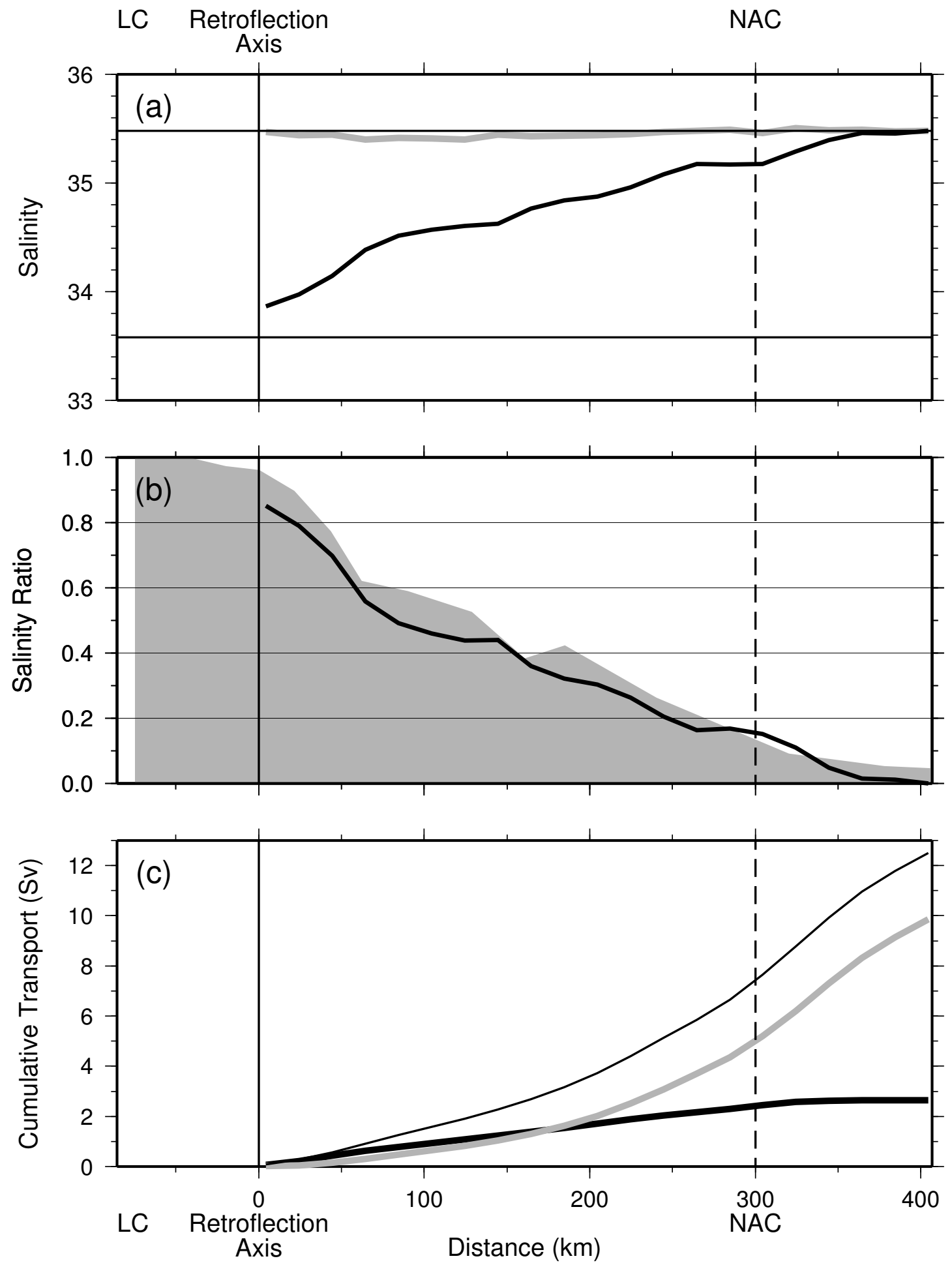

Figure 15 

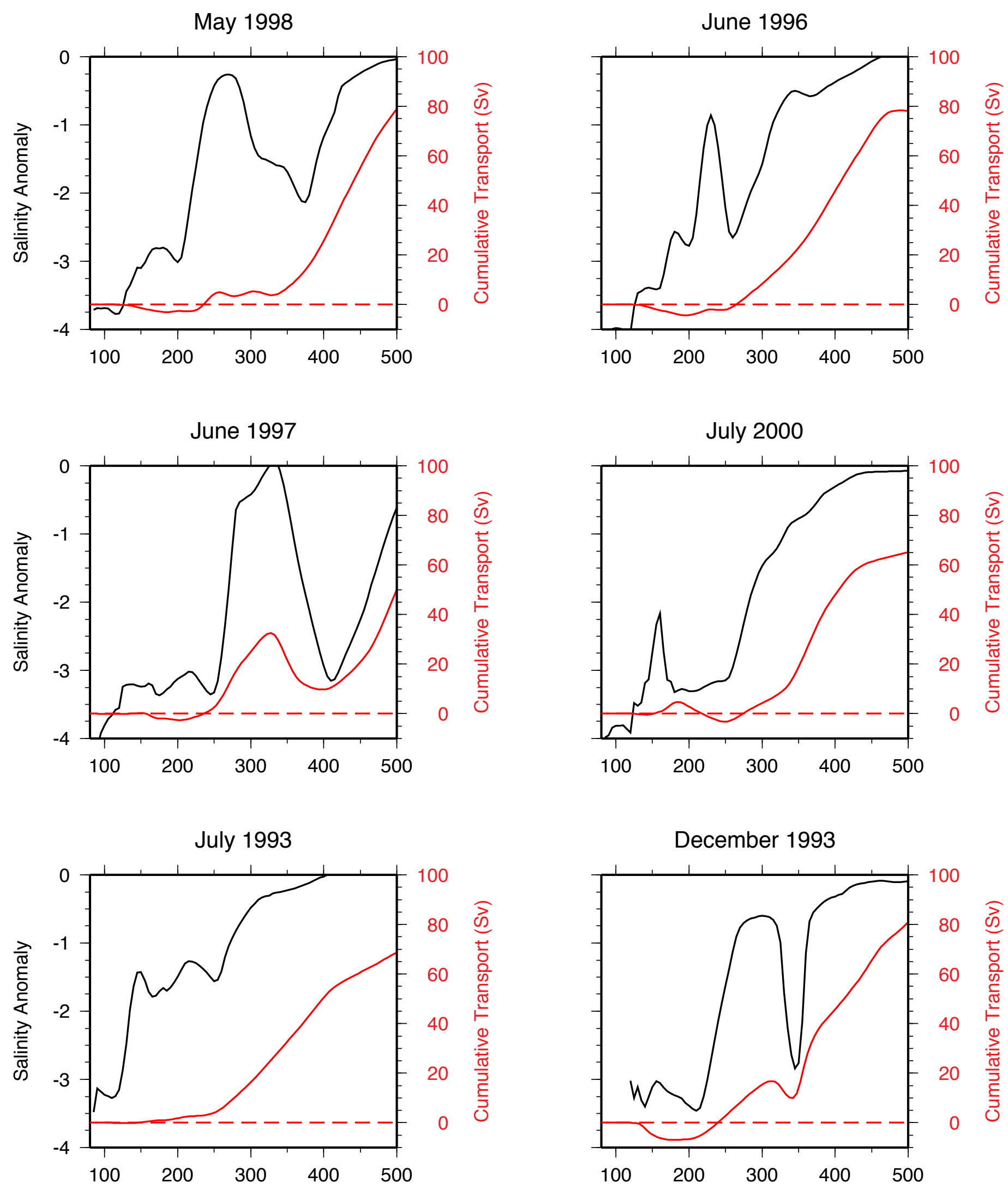

Figure 16 